\title{
8 Sartre und der kulturelle Kalte Krieg
}

Ein Wort zunächst über Wien: eine schöne tote Stadt mit verlassenen Straßen.

(Un mot sur Vienne, d'abord: une belle ville morte, aux rues désertes.)

Jean-Paul Sartre, „Was ich in Wien gesehen habe, ist der Frieden“.

(„Ce que j'ai vu à Vienne, c'est la Paix“.)

Jean Paul Sartre tritt, wie zu einem Kongreß, zur Tür herein.

Wir befragen ihn über die Welt und die Hölle.

Sartres Antwort: ,Die Welt versteht unter Welt Welt, und bis dorthin reicht meine Kompetenz.'

Anschließend wache ich auf.

Andreas Okopenko, Traumberichte. ${ }^{1}$

\subsection{Die Bühne als Ideen-Umschlagplatz}

Nach siebenmonatiger Sperrung beginnen die Wiener Theater - „einige sind halbe oder ganze Ruinen“ - von Neuem, allerdings nicht mit Neuem, sondern mit dem Programm „des guten alten Theaters“, so der Journalist Adelbert Muhr, der auch die ,richtigen“ ZuschauerInnen vermisst, die Stücke würden in einen „geistig leeren Raum “'2 hineingespielt. Das Fehlen der urbanen jüdischen Bevölkerung macht sich hier nach Sperber bemerkbar: „Wien hatte sich in der Nazizeit provinzialisiert Wiener, die in Kleidung und Gehaben Provinzlern glichen, bildeten nun die Mehr-

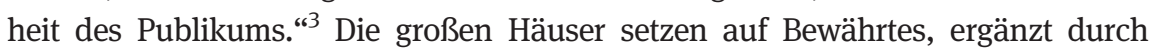
„,Mariandln“ ausländischer Provenienz““4, stellt Herbert Eisenreich fest. „Konservierung und Konservatismus geben den Ton an“, resümiert 1952 Hans Weigel in der von Melvin Lasky herausgegebenen Zeitschrift Der Monat die kulturelle Situation Österreichs, die rühmliche Ausnahme stellten junge TheatermacherInnen dar, die „mit wechselndem Glück“ unter anderem Sartre, Obey, Weisenborn und Bor-

1 Im Traum erscheint Sartre auch der Figur Jakob in Johannes Mario Simmels Hurra - wir leben noch! (Locarno 1978, S. 163): „Unser Freund schlief sehr unruhig in dieser Nacht. Immer wieder schreckte er aus gräßlichen Alpträumen auf. In ihnen sprachen mit ihm vertraulich Herren, die er nicht kannte, nie gesehen hatte, von denen er nicht das geringste wußte. Die Herren hießen Egmont Wilder, Reger Anouilh, Giovanni Sartre und Don Schönberg ... “.

2 Adelbert Muhr: Wiener Theater. Sofern es europäisch und zeitgemäß ist. In: Plan 1 (1945), Nr. 2, S. 154-158, hier S. 154.

3 Sperber: Bis man mir Scherben auf die Augen legt, S. 270.

4 Eisenreich: Prominente von unten gesehen. In: Die Zeit, 26.02.1953. 
chert auf Keller- und Zimmerbühnen brachten und so „die Ehre des österreichischen Theaters"s ${ }^{\text {“5 }}$ rtteten. Bis in die frühen sechziger Jahre gehen fast alle progressiven Impulse von den Kleinbühnen aus; die „waghalsigen ,Theater der 49““, ausgestattet mit 49 Sitzplätzen, weil Konzessionen erst ab 50 Sitzen anfallen, offerieren laut Eisenreich immer „das Interessanteste“6. Ansonsten sei das einzige Theater Wiens, in das man gehen könne, ohne enttäuscht zu werden, das sich aus mehreren dieser ,Neunundvierziger-Bühnen' entwickelnde Theater am Parkring: „Vor allem der Spielplan ist geradezu unwienerisch, nämlich aktuell, künstlerisch anspruchsvoll und weltoffen.“7 Das Theater am Parkring zählt zudem zu den Theatern, die sich am intensivsten um Sartre bemühen, während sich etwa das Burgtheater bis 1965 (Die Fliegen, Premiere: 15.02.1965, Regie: Rudolf Sellner), dem Jahr nach der Zuerkennung des (nicht angenommenen) Nobelpreises, den Autor zu spielen weigert. Zwar hat schon vor der Direktion Ernst Haeussermans (1959-1968) Burgdirektor Josef Gielen (1948-1954) „um die zeitgenössische französische Dramatik - und insbesondere um das Werk Jean-Paul Sartres“ gekämpft, scheitert aber an der bekannten „sowohl bei Katholiken, als auch bei ,extremen Linken zu beobachtenden Abneigung gegenüber dem ,Existentialismus“'“8 . Befindlichkeiten, auf die keine Rücksicht genommen werden sollte, meint in der Arbeiter-Zeitung 1950 Hans Heinz Hahnl: „Die Direktoren der großen Wiener Geschäftstheater trauen sich nicht an die existentialistischen Zeitstücke von Jean Paul Sartre heran. Zu Unrecht. Sartre ist spannend in einem doppelten Sinn: szenisch und intellektuell.“9

Einschätzungen zur Präsenz Sartres auf österreichischen Bühnen variieren je nach Perspektive: Ab Ende der vierziger Jahre wagt man sich Porpaczy zufolge

5 Weigel: Brief aus Wien: Zentrum am Rande, S. 180. Cf. auch Wolfgang Greisenegger: Das Theaterleben nach 1945. In: Aspetsberger, Frei und Lengauer (Hg.): Literatur der Nachkriegszeit, S. 223-240.

6 Eisenreich: Prominente von unten gesehen. In: Die Zeit, 26.02.1953.

7 Eisenreich: Prominente von unten gesehen. In: Die Zeit, 26.02.1953. Der Gründer des Theaters am Parkring, Helmut Schwarz, weist sich als vom Existentialismus geprägt aus, nennt sein Drama Seine letzte Berufung (1952), das im Juni 1955 im Wiener Theater Die Tribüne (Universitätsring 4) uraufgeführt wird, „ein Richterstück nach Sartre-Vorbild“ (Kerschbaumer: Wiener Festwochen zwischen Restauration und Weltgeltungsanspruch, S. 314) und bejaht konsequent die Frage, ob „das heutige Theater die Aufgabe [hat], Zeit und Welt zu reflektieren“. Helmut Schwarz: Auftrag Gerechtigkeit. Wien 1971, S. 5.

8 Hilde Haider-Pregler: „Das Burgtheater ist eine Idee ... “. Die Jahre 1945 bis 1955 - eine Zwischenzeit des österreichischen Staatstheaters? In: Haider-Pregler und Roessler (Hg.): Zeit der Befreiung, S. 84-122, hier S. 100 f. Mit der Dostojewski-Dramatisierung Die Besessenen (Premiere: 07.12.1959, Regie: Leopold Lindtberg) wird Camus schon einige Jahre vorher eine Burgtheater-Produktion (im Akademietheater) zuteil.

9 h.h.h.: Sartre im Theater der Courage. In: Arbeiter-Zeitung, 17.01.1950. 
„vereinzelt“10 an den Autor heran, für Peter Roessler ist „Sartres Dramatik im restaurierten Theaterleben nur in der Randlage platziert“11, Susanne Albrecht hingegen sieht die Stücke seit 1948 „kontinuierlich auf den Spielplänen der großen Schauspielhäuser und Kellertheater“12 Wiens stehen. Eine Annäherung erlaubt die Datenbank für österreichische Theaterinszenierungen (theadok); sie verzeichnet von 1945 bis 2000 insgesamt 110 Sartre-Inszenierungen in Österreich, elf davon in den Besatzungsjahren. ${ }^{13}$ Im selben Zeitraum ist Jean Anouilh, seinerseits der „beliebteste moderne Dramatiker“14 in Österreich (obgleich auch hier

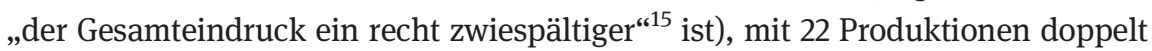
so häufig wie Sartre vertreten. Mit 16 Inszenierungen überbietet ihn auch der schon in der Zwischenkriegszeit erfolgreiche Jean Cocteau, wohingegen es zu nur vier Inszenierungen von Camus zwischen 1945 und 1955 kommt - obwohl er laut Geistiges Frankreich „zu den besten Namen der neuen französischen Literatur“ zählt und viele ,auf ihn hören und jedes seiner Stücke mit grosser Spannung erwarten“16. Auch von dem erst im Folgejahrzehnt stärker rezipierten Beckett gelangt in der Besatzungszeit nur ein Stück zur Aufführung (Warten auf Godot hat am 08.04.1954 Premiere im Theater am Parkring, Regie: Erich Neuberg). ${ }^{17}$ Einzig

10 Porpaczy: Frankreich - Österreich, S. 216.

11 Roessler: Die Rekonstruktion eines Genres, S. $361 \mathrm{f}$.

12 Albrecht: Von Molière zu Mnouchkine, S. $160 \mathrm{f}$.

13 Es folgen: 23 von 1955-1964, 20 von 1965-1974, 31 von 1975-1984, 21 von 1985-1994 und vier von 1995-2000. Cf. Brigitte Marschall und Arbeitsgemeinschaft Theaterdokumentation: 50 Jahre Theater in Österreich. Verzeichnis der Inszenierungen 1945-1995. Theadok, CD-ROM. Steinbach 2003; die Datenbank bildet das Fundament für alle folgenden Auswertungen in diesem Kapitel.

14 Porpaczy: Frankreich - Österreich, S. 216.

15 Adelbert Muhr: Wiener Premieren als literarhistorischer Exkurs. In: Plan 1 (1946), Nr. 5, S. 434-425, hier S. 425.

16 o. V.: „Die Gerechten“ von Albert Camus. In: Geistiges Frankreich, 16.01.1950. Camus sei nur „sehr selten“ (Von Molière zu Mnouchkine, S. 160) auf Wiener Bühnen zu sehen, schreibt Albrecht; er werde „generell erst in den späten fünfziger bzw. in den sechziger Jahren aufgeführt“ (Frankreich - Österreich, S. 216), erwähnt Porpaczy, wobei in der Besatzungszeit drei Stücke aufgeführt werden: Die Gerechten (cf. Kap. 5.2) im März 1951 im Wiener Volkstheater (Regie: Gustav Manker), Belagerungszustand im Wiener Volkstheater (Premiere: 31.03.1953, Regie: Gustav Manker), neuerlich Die Gerechten im November 1952 in den Grazer Kammerspielen (Regie: Ludwig Andersen) und Caligula im Wiener Theater am Parkring (Premiere: 06.06.1954, Regie: Kurt Schwarz). Insgesamt kommen nach der theadok-Datenbank bis 2000 insgesamt sieben Stücke zur Aufführung (Adaptationen ergänzen Camus' aus fünf Stücken bestehendes dramatisches (Euvre).

17 Die Existentialismus-Zuordnung erstreckt sich in Österreich bis zu Beckett, von dem der Komparatist Marius François Guyard („Godot“ am Nullpunkt. In: Wort und Wahrheit 9 [1954], 1. Halbjahr, S. 316-317) seiner vermeintlichen Eintönigkeit wegen allerdings abrät, Beckett 
zwischen 1975 und 1985 lässt Sartre mit 31 Inszenierungen alle VergleichsautorInnen hinter sich (Anouilh: 19, Cocteau: acht, Camus: sieben, und Beckett: 27), wobei Sartres Ableben im April 1980 als Anlass durchaus eine Rolle gespielt haben dürfte (cf. Kap. 9).

Verhinderte Inszenierungen und Lesungen abgezogen, verbleiben zwischen 1945 und 1955 acht größere Produktionen von sechs Sartre-Stücken. Auf Die Fliegen 1947/48 in den Wiener Kammerspielen (cf. Kap. 3.2) folgt im Jänner 1950 das Stück Die ehrbare Dirne im Theater der Courage (Regie: August Rieger, der es dort als Die respektvolle Dirne ab dem 19.02.1953 neuerlich inszeniert), das ebenfalls auf wenig Widerhall stößt. Obwohl „skandalös schlecht“ übersetzt, so das Urteil der Welt am Montag, müsste das Stück ,jeder junge, jeder ernsthafte, jeder geistig interessierte Mensch dieser Stadt kennenlernen“, was nicht der Fall sei: „Infolge schlechter Witterung des Publikums für alles, was nicht längst ,ausprobiert' und approbiert ist, finden die interessanten Veranstaltungen im leeren Saal statt.“ ${ }^{18}$ Auch der Erfolg des in den Wiener Kammerspielen dargebotenen Stücks Tote ohne Begräbnis (Premiere: 21.06.1952, Regie: Otto A. Eder) über die Konflikte innerhalb einer von Folter bedrohten RésistancekämpferInnen-Gruppe hält sich in Grenzen. Erst mit den Jahren wird dieses schon in Frankreich „,allgemein als ein Fehlschlag“19 gewertete Drama in Österreich erträglich, lässt der spätere Arbeiter-Zeitungs-Chefredakteur Manfred Scheuch 1958 anlässlich der Produktion im Wiener Studio im Settlement wissen:

Es gehört Mut dazu, ein Stück [...], das seinem Zuschauer nichts, gar nichts von der unmenschlichen Realität der Folterung erspart - eben Jean Paul Sartres „Tote ohne Begräbnis“ heute zu spielen. Vor einem knappen Jahrzehnt schon hat es ein Theater in Wien zu spielen versucht, aber nach der entsetzten Reaktion des (gutbürgerlichen) Publikums ist die Aufführung über die Premiere nicht hinausgekommen. Seither hat sich keines der subventionierten Kellertheater, von den großen Bühnen ganz zu schweigen, über dieses Drama gewagt. ${ }^{20}$

„ermüdet die glühendsten Existentialisten“: „Kennen Sie Joyce, Kafka, Faulkner und Sartre? Dann lesen Sie, bitte, Beckett nicht, denn seine einzige Originalität besteht darin, Ihnen einen Cocktail aus den bedeutendsten Romanen der genannten Dichter zu mixen.“ (S. 316) Becketts literarische Form habe, so Guyards überraschender Standpunkt, „nicht einmal mehr den Reiz der Neuheit“: „Das absurde Nichts der Existenz bis zum ,Ekel“ vorzuführen ist Sartre in seinem Roman mit einer geballten Kraft gelungen, die uns packt, wie uns das Produkt von Beckett nie packen wird.“ (S. 317) Cf. auch Hannes Schweiger: Failing better. Die Rezeption Samuel Becketts in Österreich. (Wechselwirkungen 8.) Bern 2005, S. 133-136.

18 o. V.: Die Jungen. In: Welt am Montag, 23.01.1950.

19 o. V.: Les Mains Sales (Schmutzige Hände) von Jean-Paul Sartre. In: Kulturelles, 26.04.1948.

20 Manfred Scheuch: Literatur der äußersten Situation. Jean Paul Sartres „Tote ohne Begräbnis“. In: neue generation 8 (1958), Nr. 4, S. 10. 
Dabei ist Sartres Theater zumindest von der Form her traditionell-bürgerlich (,traditionnelle, passéiste et, pourquoi ne pas le dire, passablement ,bourgeoise““21), konstatiert Jean-Pierre Sarrazac; es knüpfe, wie auch Camus' Dramen, stilistisch an das moderne Theater der 1930er Jahre an. Was schockiere, etwa am ,aufwühlende[n] Resistance-Stück “22 Morts sans sépulture, in dem nicht Deutsche foltern, sondern Vichy-Franzosen, sei der Inhalt, der neuartige existentialistische Diskurse widerspiegele. ${ }^{23} \mathrm{Zu}$ neuartig, fürchten die französischen Alliierten im Wunsch, ihr „österreichisches Publikum nicht zu brüskieren und Maßnahmen zu treffen, die ihm die Rezeption französischer Kultur erleichtern““24, was die Vermittlung existentialistischer Literatur - etwa wegen des Kollaborationsthemas - nur bedingt inkludiert (cf. Kap. 4.2 und 4.3). Sartre sei, so die verbreitete Meinung, ,zu viel' und „noch sehr ,exotisch““25, etwa für die Innsbrucker TheatergängerInnen, die 1948/ 49 und 1950/51 mit Huis clos konfrontiert werden. Die Antworten des zahlreich sich einfindenden Publikums bezeugen indes eine hohe Bereitschaft, auf die zur Schau gestellten Unerfreulichkeiten (,Schmutz und Unrat, Perversität und brünstigste Lust“) mit gründlichem Nachdenken zu reagieren und „starken Beifall“ zu spenden: Die „Problemkette von Schuld, Hölle, Verdammung [...] des überaus intellektuellen, anspruchsvollen Werkes“ habe den Zweck, „aus falscher Selbstsicherheit und schlaffer Selbstzufriedenheit“‘26 aufzurütteln, erläutert eine Rezension

21 Jean-Pierre Sarrazac: Théâtre: le palais et les catacombes. In: Gumplowicz und Klein (Hg.): Paris 1944-1954, S. 142-150, hier S. 143.

22 Es ,wurzelt vielleicht stärker als andere seiner Werke in Sartres philosophischem Bekenntnis“, so Scheuch weiter: „Sein Existenzialismus führt, unter radikalstem Verzicht auf alles Transzendente und aus der Erkenntnis der Absurdität der Existenz und der Gemeinsamkeit des Elends zum Streben nach einem neuen, illusionslosen Humanismus. [...] Darum darf auch seine Stimme nicht überhört werden, die seine Landsleute erschütternd zur Besinnung mahnt“. Scheuch: Literatur der äußersten Situation, S. 10. Ausgehend davon, dass der „Widerstandskampf des französischen Volkes“ gegen Hitlerdeutschland „eines der stolzesten Ruhmesblätter seiner Geschichte“ ist, schreibt hingegen die kommunistische Österreichische Zeitung (Karinzew: Propaganda der „Hölle“ und des „Wahnsinns“, 16.04.1947) über Sartres „Die Sieger“ (Morts sans sépulture), es sei „eine bösartige und unwahre Karikatur auf die heldenhaften Partisanen“, mehr noch, „ein Hohn auf das französische Volk und eine Schande für die französische Dramatik.“

23 Sarrazac: Théâtre: le palais et les catacombes, S. 144.

24 Porpaczy: Frankreich - Österreich, S. 223.

25 Ladner: Literarische Aktivitäten des Institut Français. Innsbruck 1946-60, S. 41.

26 Dr. Tepser: Sartre-Premiere in Innsbruck. In: Tiroler Tageszeitung, 15.05.1950. Bevor in Wien Hinter geschlossenen Türen am 06.05.1953 unter der Regie von Erich Neuberg im Theater am Parkring Premiere feiert, können unter anderem das Intime Theater in der Praterstraße im November 1947 und das Kleine Theater im Konzerthaus (vormals ,Experiment') am 19. Juni 1951 mit Bei geschlossenen Türen (Regie: Peter Weihs) „,brillieren“ (Kerschbaumer: Wiener Festwochen zwischen Restauration und Weltgeltungsanspruch, S. 311). 
der Tiroler Tageszeitung. Sartre kommentiert das „Philodrama“27 1960 im Rückblick als Stück, in dem es eigentlich nicht um Philosophie gehen sollte (,petite pièce où l'on ne parle pas de philosophie“):

Die Zuschauer glauben, daß es da etwas zu verstehen gebe. Es steckt überhaupt nichts darin. Aber wenn man nicht-philosophische Werke schreibt, während man sich mit Philosophie herumschlägt - wie ich es vor allem in den letzten zehn Jahren getan habe -, dann leidet die geringste Seite, die geringste Prosa an Brüchen. ${ }^{28}$

(Les spectateurs croient qu'il y a quelque chose à comprendre. Il n'y a rien du tout. Mais quand on fait des ouvrages non philosophiques, tout en ruminant de la philosophie comme j'ai fait surtout depuis ces dix dernières années -, la moindre page, la moindre prose souffrent de hernies. $)^{29}$

Es ist dieses zum internationalen Erfolgsstück Sartres werdende Drama Huis clos, das in weiterer Folge von österreichischen AutorInnen immer wieder aufgegriffen wird und von Milo Dor bis Wolfgang Bauer „Nachahmer“30 findet. Eine ins Detail gehende Auseinandersetzung steht hinter Robert Neumanns folgender Parodie:

(Drei Embryos in Kinderwagen.)

Jean Paul: Wo wir sind, ist klar.

Estelle: Es gibt also wirklich einen Sammel-Warteraum, in dem wir warten müssen, bevor wir - ?

Jean Paul: Bevor wir zur Welt kommen. Sprechen sie es ruhig aus. Und warum nicht? Der Gedanke, bloß einen Warteraum vernichten zu müssen, um aller Existenz ein Ende zu machen, hat seine Lockungen.

Gustave: Psychoanal hoch interessant.

Estelle: Diese Renaissance-Kinderwagen, in denen wir liegen, irritieren mich.

Jean Paul: Und wann - wenn die Frage nicht indiskret ist - gedenken Sie geboren zu werden?

27 Rudolf John: Nur Sprache und Denken. In: Kurier, 17.04.1980.

28 Jean-Paul Sartre: Literatur als Engagement für das Ganze. Interview mit Madeleine Chapsal, 1960. In: Sartre: Was kann Literatur? Interviews, Reden, Texte. 1960-1967. Hg. und mit einem Nachwort von Traugott König. Übersetzt von Stephan Hermlin, Traugott König, Joachim Ozdoba, Helmut Scheffel. (Gesammelte Werke in Einzelausgaben, Schriften zur Literatur 6.) Reinbek 1979, S. 9-29, hier S. 10 (Hervorhebung im Oritinal).

29 Sartre: Les Écrivains en personne, S. 10 f. (Hervorhebung im Oritinal).

30 So die Arbeiter-Zeitung über Milo Dors unpubliziertes Theaterstück Der vergessene Bahnhof (Ausschnitt in Stimmen der Gegenwart, 1953), das als Verarbeitung von Sartre-Einflüssen, besonders von Huis clos, aufgefasst wurde. Cf. Englerth: Literatur als Medium des Widerstands: Milo Dor, S. 99. 
Estelle: In drei Tagen. (Abwesend:) Meine Eltern bereiten eben alles für die Privatklinik vor. Vater hat Geld von der Bank geholt. Eben zählt er es. Meine Mutter scheint ein wenig Angst zu haben.

Gustave: Das Datum meiner Geburt ist noch ungewiß. Ich sehe lediglich meine zukünftige Mutter. Sie hat mich noch nicht einmal bedacht. Ich bin durch einen verwaltungstechnischen Irrtum hier.

Jean Paul: Suchen Sie Ihre Mutter mit allen Mitteln zu überreden, daß sie sich Sie noch einmal überlegt, Monsieur. Aber was hilft es? Die Menschen haben nun einmal ihre Freude daran. (Nach einer Pause, abwesend:) Ich werde in genau neun Monaten zur Welt kommen. In ganz genau neun Monaten.

Estelle: Was sehen Sie, Monsieur?

Jean Paul: Sprechen wir nicht davon! - Immerhin, meine Väter können sich sehen lassen. Warten Sie mal, sie haben die Brieftaschen draußen in ihren Überröcken gelassen. So kann ich mir wenigstens ihre Visitenkarten ansehen. Der erste ist offenbar ein Däne. Warten Sie mal, jetzt kann ich's lesen. Kierke-gaard.

Estelle: Und der andere?

Jean Paul: Einen Augenblick. (Enttäuscht) Ah, un Boche. Heid - einen Augenblick, Heidegger. Warum lachen Sie, Mademoiselle?

Estelle: Entschuldigen Sie. (Lacht:) Weil Ihre Frau Mama Ihnen gleich zwei Väter gibt.

Jean Paul: Drei. Da hat noch so ein Tänzer dazwischengefunkt.

Gustave: Wie heißt er?

Jean Paul: Nihilijinski.

Estelle: Was gedenken Sie zu werden, Monsieur?

Jean Paul: Gymnasialprofessor.

Gustave: Und sonst nichts?

Jean Paul: Und sonst nichts. Manche Gymnasialprofessoren haben es mit der klassischen Philologie. Warum sollte es einer nicht ebensogut mit dem Nihilijinskismus haben?

Gustave: Psychoanal außerordentlich interessant.

Estelle: Was ich werden soll, kann ich noch nicht sehen.

Jean Paul: Einfach. Sie werden selbstverständlich eine Dirne, die an Säuferwahnsinn zugrunde geht, der natürlich durch Ihre chronischen Krampfadern etwas beschleunigt wird. Deshalb wird ja auch Ihre Geliebte aus Verzweiflung Selbstmord begehen.

Estelle: Meine Geliebte?

Jean Paul: Warum nicht? Natürlich nur, soweit Sie sich nicht der Sodomie hingeben. Mit einem Dackel.

Gustave: Psychoanal ist das ganz außerordentlich -

Estelle: Gibt es denn hier kein Riechsalz? Man vergeht vor diesem - Nachbar, euer Fläschchen!

Jean Paul (unerbittlich): Außerdem werden Sie Plattfüße haben!

Estelle (wird ohnmächtig): Ahh.

Jean Paul: Ich möchte meine Mutter vergewaltigen!!

Gustave (schwach): Plüschoanal ist das geradezu existentionell.

Estelle (erwachend): Monsieur, Ihre Windeln! Was haben Sie da gemacht?

Jean Paul: Tut nichts, machen wir weiter! ${ }^{31}$

31 Neumann: Theatralisches Panoptikum 4, S. 544-546 (Hervorhebung im Original). 
Neumanns Parodie - die über den Dramenstoff hinaus einige in L'Etre et le Néant behandelte Themenkomplexe wie Psychoanalyse und Homosexualität einbezieht, weiters philosophische Einflüsse von Kierkegaard und Heidegger, Biographeme („Gymnasialprofessor“) sowie, als unverzichtbare Ingredienz in existentialistischer Literatur, einige Obszönitäten - schleicht sich „mit Hilfe der zunächst harmlosen Mimikry in die Welt des literarischen Opfers ein“, so der Autor, um in weiterer Folge „das so gestohlene Idiom“ $\mathrm{zu}$ verwenden und „das Opfer zu attackieren, zu entlarven [...] durch diese un-gutmütige, un-humorige Aggression“ ${ }^{32}$.

Auf skurrile Weise verwertet Wolfgang Bauer, dessen Frühwerk einen deutlichen „Einfluss von Ionesco und Sartre“33 erkennen lässt, Huis clos speziell im 1961 entstandenen Einakter Batyscaphe 17-26 oder Die Hölle ist oben. Hierin begleitet ein Reporter eine Gruppe von Verstorbenen (eine Frau, einen Mann, einen Mörder, einen Kleeianer, einen Komponisten und einen Surrealisten) in einer Tauchkugel ins Jenseits und erstattet telefonisch Bericht über die Geschehnisse an Bord. Während die meisten InsassInnen sich nur schwer mit der neuen Situation abfinden, beschließt die Frau: „Oben ist die Hölle! Die vielen Menschen ... einer furchtbarer als der andere ... hier ist es viel schöner. “34 Sartres Stück wird selten ohne Einbindung des hier angedeuteten und zum Signum gewordenen Ausspruchs, die Hölle seien die anderen („l'Enfer, c'est les Autres“35), literarisch aufgegriffen. Wiederholt auf das negative Menschenbild angesprochen, das der Formel zugrunde liegen müsse, berichtigt Sartre, das Miteinander sei zwar per se konfliktreich, infernalisch jedoch nur im Falle ,schlechter Beziehungen, in denen sich das für seine Selbsteinschätzung grundsätzlich auf andere angewiesene Ich in vollkommene Abhängigkeit von diesen begebe („dans la totale dépendance d’autrui“: „Et alors en effet je suis

32 Robert Neumann: Zur Ästhetik der Parodie. In: Neumann: Die Parodien, S. 551-563, hier S. 556.

33 Korte: Österreichische Literatur der Gegenwart, S. 87.

34 Wolfgang Bauer: Batyscaphe 17-26 oder Die Hölle ist oben. In: Bauer: Einakter und frühe Dramen. Hg. von Gerhard Melzer, mit einem Nachwort von Manfred Mixner. (Werke in sieben Bänden, 1.) Graz, Wien 1987, S. 49-72, hier S. 69. Von der Zeitschrift News (Pascher, Stroh, Zobl: Lesetips für hundert Jahre, 01.07.1999) nach seinem Lieblingsbuch gefragt, antwortet Bauer: „Albert Camus: Der Fremde. Hat mich zutiefst erschüttert, das irrationale Getriebensein und die plötzliche Bewußtwerdung des Absurden eines gesamten Lebens.“

35 Sartre: Huis clos, S. 128. 
en enfer“36). Diese Abhängigkeit veranschaulicht der Einakter Huis clos an den Hauptfiguren Garcin, Inès und Estelle, die sich posthum in einer als Second Empire-Salon eingerichteten Hölle auf ewig zueinander verdammt finden. Weder erweist sich der sie dorthin eskortierende garçon als Henker, noch erwarten sie Foltermaßnahmen im traditionellen Sinne: Sie selbst übernehmen diese Aufgaben für die jeweils anderen („,chacun le bourreau des deux autres“37), indem sie deren Anstrengungen, ein positives Bild von sich zu vermitteln, vereiteln. „[L]'Enfer, c'est les Autres“ wird allerdings meist wörtlich genommen, um unerträgliche zwischenmenschliche Situationen $\mathrm{zu}$ beschreiben, so in Brigitte Schwaigers autofiktionalem Bericht Fallen lassen (2006):

\begin{abstract}
Wären die Krankenschwestern (und auch die Psychiater und Pfleger) spezialisiert und würden sie nicht so viel Bürokratisches erledigen müssen und das Essen nicht austeilen müssen, bei höheren Gehältern, bei neuen Bauten, es könnte eine ganz andere Psychiatrie geben als die, die vor hundert Jahren hier die angeblich so schönen Pavillons erhielt. Was nützt mir Jugendstil, wenn ich meine, in einem Alptraum, im Fegefeuer zu sein, in der Hölle: mitgebrachtes eigenes Leid und das, das die Mitpatienten einem verursachen, ich muss an Sartres Theaterstück Huis clos denken, in dem er sagen lässt: „Die Hölle, das sind die anderen. “38
\end{abstract}

Die Häufigkeit, mit der das Stück von AutorInnen aufgegriffen wird, spiegelt dessen Gewicht in der Aufführungsgeschichte von Sartres Dramen. Von den zwölf in theadok gelisteten Stücken, die bis $2000 \mathrm{zu} 110$ Inszenierungen gelangen, entfallen auf Huis clos (1944) 36, auf Les Mains sales (1948) 18, auf Les Mouches (1943) zwölf, auf La Putain respectueuse (1946) elf, auf die Euripides-Adaptation Les Troyennes (1965) zehn, auf Morts sans sépulture (1946) sechs, auf die Dumas-Adaptation Kean (1954), Le Diable et le bon Dieu (1951) und Les Séquestrés d'Altona (1959) je vier, auf das Drehbuch Les jeux sont faits (1947) drei sowie auf das Scenario L'Engrenage (1969 [1948]) und das Polit-Stück Nekrassov (1955) je eine.

36 Jean-Paul Sartre: Huis clos (1965). In: Sartre: Un Théâtre des situations, S. 281-284, hier S. 282.

37 Sartre: Huis Clos, 282.

38 Schwaiger: Fallen lassen, S. 46. 
Dass der politisch aktive Sartre nach 1945 kaum mehr Zeit für Prosa findet, $^{39}$ neue Theaterstücke jedoch weit über das Kriegsende hinausreichen, weckt bei KritikerInnen den Verdacht, dass Letztere primär politische Absichten verfolgen. Nachdem für einige Jahre vom jungen Theater geradezu erwartet wurde, unmittelbar aus dem gegenwärtigen Leben zu schöpfen (es gibt, schreibt Peter Rubel 1946/47 im Plan, „kein eigentlich ,unpolitisches“ Theater: jede Kunst ist irgendwie immer auch ,politisch ${ }^{\text {“40 }}$ ), sorgt ein solcher Modus im Zuge der Verschärfung des Kalten Kriegs zunehmend für Unmut. So behauptet Chastaing, für Sartre sei die Literatur „ein Heilmittel gegen die Mängel der philosophischen Ausdrucksweise“, die zu komplex für propagandistische Zwecke sei; daraus erkläre sich, „daß die Philosophen sich heutzutage in Dramatiker und Romanciers verwandeln, damit die Leser und Zuschauer zu Mitarbeitern, ja Komplizen ihrer Philosophie werden können.“"41 Der erste L'Être et le NéantÜbersetzer Justus Streller stimmt 1952 so weit zu, dass Sartres Anliegen „aus seinen Dramen erschlossen werden“ müssen, die „als Anwendungs- oder Demonstrationsbeispiele der Sartreschen Philosophie“ gelten können, allerdings: „Die Ansichten darüber, was er eigentlich meint, gingen ziemlich weit auseinander, weil die Dramen auf die Menschen verschieden wirkten und verschieden gedeutet wurden. “42 Für diese Bemerkung liefert die Rezeption in Österreich, wo Sartre besonders „durch dieses oder jenes Theaterstück “43 und durch die begleitende, das dramatische Polarisierungsvermögen oft potenzierende Berichterstattung bekannt geworden ist, den eindrücklichsten Beweis: Die schmutzigen Hände - mit Inszenierungsabsagen, medialen Gefechten, Boy-

39 Dies liege laut Sartre jedoch nur an Zeitnot, nicht an Desinteresse: „Ich habe Romane und Theaterstücke schreiben wollen, lange bevor ich wußte, was Philosophie ist. Ich will es noch immer, ich habe es mein ganzes Leben gewollt.“ („,'ai voulu écrire des romans et du thêâtre bien longtemps avant de savoir ce qu'était la philosophie. Je le veux encore, je l'ai voulu toute ma vie.“) Sartre: Literatur als Engagement für das Ganze, S. 11. (Sartre: Les Écrivains en personne, S. 13.) Sartres Prosawerk umfasst den Roman La Nausée (1938) und die Erzählungen Le Mur (1939), worauf die Romantrilogie Les Chemins de la liberté, bestehend aus L'Âge de raison (1945), Le Sursis (1945) und La Mort dans l'âme (1949), folgt. Mit Ausnahme von Letzterem erscheinen alle Werke, bevor die literarische Sartre-Rezeption in Österreich (größtenteils ab 1949/50) beginnt.

40 Peter Rubel: Die Verpflichtung des Theaters. In: Plan 1 (1946/47) Nr. 12, S. 978-980, hier S. 979 (Hervorhebung im Original).

41 Chastaing: Existentialismus und Betrug, S. 274, 275.

42 Streller: Zur Freiheit verurteilt, o. S.

43 Benedek: Zweimal Jean Paul Sartre. In: Tagebuch, 03.01.1953. 
kott und Zensur - wird die Aufregung, die Sartres erstes Stück Die Fliegen vier Jahre zuvor in Deutschland entfacht (cf. Kap. 3.2), noch übertreffen und den weiteren Transferverlauf prägen.

\subsection{Wendepunkt Wien: Schmutzige Hände und der „Völkerkongress für den Frieden“}

Als einer von 1880 Gästen aus 85 Ländern, die sich vom 12. bis in die Nacht des 20. Dezember 1952 beim „Völkerkongress für den Frieden“ im Wiener Konzerthaus aufhalten, hat Sartre den Eindruck, von Menschen aller Verhältnisse und verschiedenster Meinungen umgeben zu sein (,des hommes de toutes conditions et d'opinions très diverses“44). Ersteres lässt sich leicht belegen: 326 ArbeiterInnen sind zugegen, 160 Angestellte, 157 WissenschaftlerInnen und Angehörige des Gesundheitswesens, 94 PädagogInnen, 86 JuristInnen, 75 TechnikerInnen, 65 Geistliche, 63 Industrielle, Kaufleute und GroßgrundbesitzerInnen, 56 BildhauerInnen, ArchitektInnen, MalerInnen und RaumausstatterInnen, 55 in der Landwirtschaft Tätige, 46 PolitikerInnen, 20 SchauspielerInnen und Filmschaffende, 19 MusikerInnen und KomponistInnen, acht SportlerInnen und insgesamt 189 SchriftstellerInnen, darunter Ilya Ehrenburg, Louis Aragon und Georg Lukács. ${ }^{45}$ Durch diese Heterogenität erscheint die vom kommunistischen Weltfriedensrat organisierte Veranstaltung, anders als die vorangegangenen „Weltkongresse der Kämpfer für den Frieden“ in Paris und Prag (im April 1949) sowie in Warschau (im November 1950), nun nicht mehr als von „deutlich prosowjetischer Tendenz “46. Leicht werde es für die Amerikaner jedenfalls nicht, den Kongress als kommunistisch auszugeben, meint die prosowjetische Zeitschrift Tagebuch angesichts der Tatsache, dass hier „englische Labour-Abgeordnete, französische Konservative, italienische Monarchisten, westdeutsche Kirchenführer, australische Gewerkschafter, persische Nationalisten, indische Parlamentarier“"47 aufeinandertreffen. Dennoch besteht auf der Gegenseite kein Zweifel an den Absichten dieses neuen ,appeal to pacifists and neutralists of all possible shades“, wie ein geheimes NATO-Dokument vom

44 Jean-Paul Sartre: Le Congrès de Vienne. In: Le Monde, 01.01.1953. Cf. auch Juliane Werner: Sartre in Austria. Boycott, Scandals, and the Fight for Peace. In: Sartre Studies International 23 (2017), Nr. 2, S. 1-18.

45 Daten entnommen aus: Völkerkongreß für den Frieden, Wien, vom 12. bis 20. Dezember 1952. Reden und Dokumente, Beilage der Österreichischen Friedenszeitung. Wien 1952, S. 56.

46 Mugrauer: Eine „rein kommunistische Angelegenheit“?, S. 132.

47 o. V.: Da die Diplomaten versagen, verhandeln die Völker in Wien. In: Tagebuch, 11.10.1952. 
November 1952 festhält; der Weltfriedensrat habe seine Friedens-Kampagne ausgeweitet ,with a view to raking in all those who, for any reason whatsoever, were in favour, or thought they were in favour, of maintaining peace. ${ }^{\text {"48 }}$ Die Strategie, die unpolitische Ausrichtung des Kongresses hervorzuheben, hat Erfolg: Rund ein Viertel der Teilnehmer gilt als ohne Nahverhältnis zum Kommunismus. Sartres Vernehmen nach sind wenig KommunistInnen zugegen; Simone de Beauvoir schätzt in La Force des choses ihren Anteil auf ein Fünftel der BesucherInnen. ${ }^{49}$

Als Beitrag zur Beendigung des Kalten Kriegs einberufen, ist der wichtigste Beschluss des „Völkerkongresses für den Frieden“ die von einem 19-köpfigen DelegiertInnen-Komitee „in der ganzen Welt“ bekanntzumachende „Adresse an die fünf Großmächte“50, welche Verständigung und in einen Friedenspakt mündende Verhandlungen fordert. Spezifizierungen des Anliegens (Abrüstung, Verbot von Atomwaffen) stellen die Ausnahme dar, „eine tatsächliche, kontroversielle Diskussion fand kaum statt“"51, wie Manfred Mugrauer schreibt. Unverfänglich fällt schon Sartres Ansprache am Eröffnungsabend aus; er hält sich in seinem Plädoyer zur internationalen Befriedung („pacification internationale“52) an „einfache, sogar primitive Worte“53, wundert sich Günther Steffen in Die Zeit. Sartre würdigt den Dialog konkreter Menschen - anstelle des als abstrakt empfundenen PolitikerInnen-Vorgehens, über einen atomaren, von der Verantwortung des Einzelnen völlig losgelösten Krieg zu entscheiden ${ }^{54}$ - und begeistert sich für die Zusammengehörigkeit und Rücksichtnahme vor Ort („dans la grande salle du Konzerthaus où nous faisions au début plus ou moins figure d'invités, chacun s'est senti chez soi, chacun s'est reconnu, avec son peuple, dans les motions finales“"55). Zurück in Paris berichtet er am 23. Dezember 1952 vor einem Massenpublikum im Vélodrome d'Hiver von dieser außergewöhnlichen Erfahrung, die in ihrem Vermögen, Hoffnung $\mathrm{zu}$ spenden, eine der drei wichtigsten seines Erwachsenenlebens sei (neben dem Front populaire 1936 und der Libération 1944). ${ }^{56}$

48 [H. Hjorth-Nielsen], North Atlantic Council: NATO Secret Document, 10.11.1952 (AC/24-D/16), S. 3. http://archives.nato.int/uploads/r/null/9/1/9177/AC_24-D_16_ENG.pdf (einges. 09.01.2019).

49 Cf. Beauvoir: La Force des choses, Bd. 2, S. 20.

50 o. V.: Völkerkongreß für den Frieden, S. 3.

51 Mugrauer: Eine „rein kommunistische Angelegenheit“?, S. 142.

52 Jean-Paul Sartre: Intervention de M. Jean-Paul Sartre. In: Congrès des Peuples pour la Paix, Service d'Information [Vienne], 13.12.1952.

53 Günther Steffen: Pilgrim des „Friedens“. Sartres erster Schritt zur Selbstkritik. In: Die Zeit, 25.12.1952.

54 Sartre: Intervention de M. Jean-Paul Sartre, Service d'Information [Vienne], 13.12.1952.

55 Sartre: Le Congrès de Vienne. In: Le Monde, 01.01.1953.

56 Cf. Jean-Paul Sartre: Ce que j’ai vu à Vienne, c'est la Paix. In: Les Lettres françaises, 01.08.01.1953. 
Groß ist die Verblüffung über den Auftritt des vier Jahre zuvor bei der Vorgängerveranstaltung (dem „Weltkongress der Intellektuellen für den Frieden“ in Breslau) als Hyäne mit Füllfederhalter („hyène à stylographe“) verunglimpften Feind Nr. 1 der sowjetischen SchriftstellerInnen (,ennemi $n^{\circ} 1$ des écrivains soviétiques“" ${ }^{67}$ ). Ernst Fischer erinnert sich genau an die Flüche Alexander Fadejews, des Sekretärs des UdSSR-Schriftstellerverbandes, über die „modernistische Philosophie à la Sartre, die den Menschen auf allen Vieren kriechen lassen möchte“:

Könnten die Schakale lernen, auf der Schreibmaschine zu schreiben, oder könnten die Hyänen sich des Füllfederhalters bedienen, so würden sie wahrscheinlich ähnliche Werke schaffen wie die Henry Miller, Eliot, Malraux und die übrigen Sartre-Typen. Die Propagierung des Verbrechens, der Sittenverderbnis, der tierischen Instinkte braucht die Reaktion, um die Volksmassen in ihr willenloses Werkzeug zu verwandeln. ${ }^{58}$

Manès Sperbers Variante der Botschaft aus Breslau lautet,

daß sich der Westen kulturell in der letzten Phase seines unaufhaltsamen Niedergangs befinde: daß seine Literatur wie seine anderen Künste dekadent und steril seien, daß zum Beispiel Malraux, aber auch Sartre, der damals noch kein Sympathisant war, und so viele andere Intellektuelle ,Hyänen mit Schreibmaschinen im Dienste von Wallstreet‘ wären. ${ }^{59}$

Die im selben Jahr veröffentlichte literaturtheoretische Abhandlung Qu'est-ce que la littérature? (1948) macht klar, dass für Sartre eine Verbindung mit der Kommunistischen Partei außer Frage steht, obwohl diese über den zur Verwirklichung der klassenlosen Gesellschaft nötigen Zugang zur Masse verfügt. ${ }^{60}$ Dass Sartre sich 1952 nun scheinbar plötzlich zur Kooperation bereit sieht, liegt am inzwischen evident gewordenen Scheitern seiner Bemühungen um einen ,Dritten Weg (,la fameuse troisième force ou troisième voie“61), die Erschaffung einer politisch linken Bewegung, die demokratischer als die kommunistische (PCF) und revolutionärer als die sozialdemokratische (SFIO) sein sollte: Das zu diesem Zweck zuvor von ihm mitbegründete kurzlebige Rassemblement démocratique révolutionnaire (R.D.R.; 1947/1948-1949) tritt an gegen die Übel des Kapitalismus, die Mängel einer bestimmten Sozialdemokratie und die Begrenzungen des stalinistischen Kommunismus (,les pourrissements de la démocratie capitaliste, les faiblesses et les tares d'une certaine social-démocratie et la limitation du commu-

57 Sartre: Sartre, S. 96.

58 Ernst Fischer: Das Ende einer Illusion. Erinnerungen 1945-1955. Wien, München, Zürich 1973, S. 250.

59 Sperber: Bis man mir Scherben auf die Augen legt, S. 245.

60 Cf. Sartre: Qu'est-ce que la littérature?, S. 317.

61 Sartre: Sartre, S. 84. 
nisme à sa forme stalinienne“62), wie der im März 1948 veröffentlichte „Appel“ seines Komitees verkündet. Gedacht als eine sich ständig anpassende Vermittlung zwischen der UdSSR und den USA auf sozialistischer Ebene (,une médiation constamment changeante entre l'U.R.S.S. et les U.S.A. sur le plan socialiste“63), schwenkt das R.D.R. bald nach Westen. Seinerseits den anderen Weg gewählt zu haben, führt Sartre konkret auf drei politische Erfahrungen zurück: seine 1951 beginnende Unterstützung der KommunistInnen zugunsten des Matrosen Henri Martin, der für seinen Aufruf gegen den Indochina-Krieg wegen Sabotage verurteilt wurde; ${ }^{64}$ weiters den kommunistischen Protest gegen den am 28. Mai 1952 in Paris eintreffenden US-amerikanischen General Matthew Ridgway, dem angelastet wird, als Kommandant der UNO-Truppen während des Koreakrieges biologische Waffen gegen nordkoreanische und chinesische Gegner eingesetzt zu haben; zuletzt bekräftigt die sich im Zuge dieser Demonstration ereignende Verhaftung des Generalsekretärs der Parti Communiste, Jacques Duclos, Sartres Beschluss, compagnon de route zu werden: Die Geschehnisse erweckten in ihm den Wunsch, den Marxismus noch einmal näher anzusehen, und ein Gefühl für den Klassenkampf, dass ihn nie verlassen habe („un désir de revoir le marxisme, un sens de la lutte des classes qui ne m’a plus quitté ${ }^{* 65}$ ). Die französischen Kulturbeauftragten in Wien setzen die österreichischen LeserInnen im Oktober 1952 von Sartres neuer Überzeugung in Kenntnis, „dass in den jetzigen Verhältnissen eine gewisse Zusammenarbeit mit dem Kommunismus der einzige mögliche Weg sei“"66, zunächst ohne größeren Widerhall.

Sartres erste Wien-Reise steht am Ende dieses Jahres, das von einer theoretischen Beschäftigung mit dem Kommunismus geprägt ist (die ersten beiden Teile von „Les Communistes et la Paix“ erscheinen im Sommer und Herbst 1952 in Les Temps modernes), und in dem sich der endgültige Bruch mit den einstigen Freunden Maurice Merleau-Ponty und, nach drastischen Verbalattacken, Albert Camus vollzieht. ${ }^{67}$ Der Auftritt in Wien führt diesen Trend fort: Viele dis-

62 Jean-Paul Sartre et al.: Appel du comité pour le Rassemblement Démocratique Révolutionnaire. In: Esprit 1948, Nr. 143 [März], S. 464-466, hier S. 464.

63 Sartre: Sartre, S. 90.

64 Cf. Jean-Paul Sartre: L’Affaire Henri Martin. Paris 1953.

65 Sartre: Sartre, S. 111. Für eine Betrachtung der Hintergründe von Sartres Weggenossenschaft cf. Alfred Betschart: Sartre und die Sowjetunion - ein Beispiel für Ethik in Situation. In: Knopp und Von Wroblewsky (Hg.): Carnets Jean-Paul Sartre: Reisende ohne Fahrschein. (Jahrbücher der Sartre-Gesellschaft 3.) Frankfurt am Main 2012, S. 37-60.

66 Armand Jacob: Die Auseinandersetzung Sartre-Camus. In: Geistiges Frankreich, 13.10.1952. 67 Eine konzise Darstellung von Sartres Bruch mit Merleau-Ponty, Camus und Aron liefert der dritte Part („Les années Sartre“) von Michel Winocks Studie Le Siècle des intellectuels (Paris 1999 [1997]). 
tanzieren sich von ihm, mit oder ohne Eklat, Simone de Beauvoir zufolge aufgrund tiefer Meinungsverschiedenheiten oder weil sie ihn kompromittierend fanden (,,avec plus ou moins d'éclat, soit par un profond désaccord, soit parce qu'ils le trouvaient compromettant“68). Während sich Sartres Annäherung an die KommunistInnen über mehrere Jahre zieht, macht ihn seine Rede beim international sichtbaren Friedenskongress, „die erste nach seiner Wandlung“69, offiziell zum Weggenossen, so seine Biographin Annie Cohen-Solal: Öffentlich zum compagnon de route wird er also nicht in dem Moment, als die Mehrzahl der Intellektuellen nach 1945 es sind, sondern sieben Jahre später, als angesichts des inzwischen publik gewordenen Ausmaßes sowjetischer Straflager viele ihre anfängliche Haltung aufgeben. ${ }^{70}$ Sartre beschließt diese Seite der Gewalt auszublenden, da er die Sowjetunion (Lenin zitierend) für einen an sich zu verteidigenden historischen Wert (,en elle-même une valeur historique à défendre“ $^{\text {“71) }}$ hält. Sperber moniert diesbezüglich:

Sartre hat niemals die Existenz des Gulag geleugnet, aber jene hemmungslos bekämpft und herabgesetzt, die diese Wahrheit verbreiteten, denn man mußte, meinte er, unter allen Bedingungen den Glauben des Proletariats an Stalin und an den sozialistischen Charakter der Sowjetunion bewahren. Sartre, der intellektuell einflußreichste und törichteste Propagandist der falschen Alternative, verlangte später, daß man zu allem Übel schweigen sollte, das Rußland und die kommunistische Bewegung in der ganzen Welt anrichteten. Und wo es unmöglich war, es zu verheimlichen, galt es, Gründe dafür zu finden, warum es trotz allem notwendig blieb zu den Kommunisten zu stehen und ihre Gegner, die ,Hunde', zu bekämpfen. ${ }^{72}$

68 Beauvoir, La Force des choses, Bd. 2, S. 21. In diesem Wandel endet das von manchen BeobachterInnen als willkürlich beanstandete „,être engagé“ without identifying the cause“ (Anders: On Sartre [LIT], S. 16) des Existentialismus. So kommentiert der 1938 von Wien nach Kalifornien emigrierte Historiker und Philosoph Eric Voegelin am 21. Oktober 1952 in einem Brief an Robert B. Heilman: „I myself wondered all the time where that sort of atheistic existentialism would end; for the attitude of ,engagement ' without being concretely engaged could not be maintained forever. To my pleasure it ended where according to my analysis of Gnosis it should end. The Sartre case is one more illuminating item in the breakdown of intellectualism.“ Eric Voegelin: Robert B. Heilman and Eric Voegelin. A Friendship in Letters. 1944-1984. Edited with an introduction by Charles R. Embry, foreword by Champlin B. Heilman. Columbia/MO 2004, S. 114f. Cf. auch Eric Voegelin: Published Essays 1953-1965. (The Collected Works of Eric Voegelin 11.) Missouri 2000, S. 224-251.

69 Hans Heinz Holz: Die abenteuerliche Rebellion. Bürgerliche Protestbewegungen in der Philosophie. Stirner, Nietzsche, Sartre, Marcuse, Neue Linke. Darmstadt und Neuwied 1976, S. 163.

70 Cohen-Solal: Sartre, S. 569, 579.

71 Jean-Paul Sartre: Les Communistes et la Paix. In: Sartre: Situations, VI. Problèmes du marxisme, 1. Paris 1964, S. 92.

72 Sperber: Nur eine Brücke zwischen Gestern und Morgen, S. 44. 
Sartres „ultra-bolchevisme““73, wie es der einstige Freund Merleau-Ponty nennt, seine Neigung, „das Proletariat mit der kommunistischen Partei und diese mit der Sowjetunion und schließlich mit Stalin zu identifizieren“74, löst Befremden in der gauche intellectuelle aus, die zu Sartres Enttäuschung nicht nach Wien gereist war. Monatelang durch die Medien beeinflusst, sei sie misstrauisch geworden, vermutet er, pessimistisch, resigniert und im Glauben, der Kongress sei nur ein Manöver (,[p]ersonnellement, je connais beaucoup de gens très honnêtes qui devraient être ici à nos côtés - et qui n’y sont pas. Pourquoi? Eh bien par pessimisme, par résignation, et puis on leur a fait craindre que le congrès ne soit une manœuvre“75). Auf der Gegenseite herrscht eine derartige Irritation über Sartres Wende, dass über Zwang und Bestechung spekuliert, zumindest aber der Verrat einstiger Ideale festgestellt wird, was sich in der Presse-Berichterstattung spiegelt: „Er war nicht mehr dazu verurteilt, frei zu sein. Und er brauchte auch nicht mehr zu wählen. Das taten jetzt andere für ihn.“76 Sartres wiederholte Beteuerung, in niemandes Auftrag zu agieren, nur aus den eigenen Friedensabsichten für die Welt heraus (die „,coexistence pacifique fondée sur des échanges Est-Ouest, réunification de l'Allemagne sans modification du régime économique des deux zones, paix en Indochine“ und die „admission de la Chine à l’O.N.U.“77), überzeugt wenige. Die meisten erklären sich die Kongress-Teilnahme von Nicht-KommunistInnen mit deren Naivität: Fritz Fassbinder etwa gibt sich in der von der amerikanischen Besatzung initiierten Zeitschrift Kontinente „erstaunt über die Naivität eines scharfsichtigen und beachtenswerten Philosophen“, der paradoxerweise „Frieden suchend in Verein mit der sowjetischen Weltfriedensbewegung“78 inzwischen dogmatisch geworden sei. Der Anti-Kommunist Friedrich Torberg, der in der von ihm gegründeten und von der CIA unterstützten Kulturzeitschrift FORVM das Geschehen als „ein sehr aufregen-

73 Maurice Merleau-Ponty: Les Aventures de la dialectique. Paris 1955, S. 131-271.

74 Sperber: Nur eine Brücke zwischen Gestern und Morgen, S. 41. Cf. Vincent von Wroblewsky: Jean-Paul Sartres Engagement für den Frieden. In: Deutsche Zeitschrift für Philosophie 33 (1985), Nr. 9, S. 797-806.

75 Sartre: Intervention de M. Jean-Paul Sartre, Service d'Information [Vienne], 13.12.1952.

76 Steffen: Pilgrim des „Friedens“. In: Die Zeit, 25.12.1952. Häufig werden in der Folge seine früheren Aussagen gegen Sartre eingesetzt, wie von Fritz Fassbinder (Quo vadis, Jean-Paul Sartre? In: Kontinente 8 [1955], Nr. 6, S. 30-34, hier S. 34): „Der Bindung oder Bindungslosigkeit Sartres setzen wir unsere feste, absolute Bindung entgegen - der sowjetische Hammer tötet und die sowjetische Sichel mäht Menschen und nicht Gras oder Frucht. - Wir wollen einen Sartresatz für uns verwenden: ,Da wir noch frei sind, werden wir nicht mit den Wachhunden der Kommunistischen Partei zusammengehen.““

77 Jean-Paul-Sartre: Interview par Paule Boussinot. In: Contat und Rybalka (Hg.): Les Écrits de Sartre, S. 252. [Zuerst in: Défense de la Paix. Numéro spécial, décembre 1952.]

78 Fassbinder: Quo vadis, Jean-Paul Sartre?, S. 33, 34, 31. 
des Schauspiel“ empfindet, sieht Sartre nicht als naiv an, dieser wisse vielmehr genau, was er tue:

Denn Jean Paul Sartre unterscheidet sich von den meisten intellektuellen Mitläufern des Kommunismus dadurch, daß er intelligent ist. Freilich macht das sein Mitläufertum nur desto rätselhafter und die Wahrscheinlichkeit, daß es nicht lange dabei bleiben wird, nur desto größer. [...] Ganz gewiß ist er intelligenter als alle die Tröpfe, die seiner „Bekehrung zum Kommunismus“ Beifall klatschen und sie schmunzelnd exploitieren. Es wäre sogar möglich, daß er ihnen insgeheim genau jenes Gefühl entgegenbringt, das sonst immer sie den Exploitierten entgegenbringen: Verachtung. Sogar möglich, daß nicht sie ihn exploitieren, sondern er sie. Und vielleicht - man kann das bei intelligenten Menschen nie wissen - vielleicht ist er sogar ein Zyniker und noch nicht ganz verloren. ${ }^{79}$

Sartre beschwert sich mehrfach über die für sein Empfinden schwarzweißen Erklärungsangebote: Nicht-kommunistische KongressteilnehmerInnen wie er würden automatisch wahlweise als hinters Licht Geführte oder KomplizInnen (,des dupes ou des complices“80), als idiotisch (,un imbécile“) oder niederträchtig (,un salaud“"81) erachtet. Zwar gehört er selbst nicht zu den MeinungsführerInnen (wie die sowjetischen Schriftsteller Simonow, Fadejew und Ehrenburg, die chinesische Politikerin Song Qingling, die französischen Politiker Yves Farge und Pierre Cot sowie der dem Weltfriedensrat präsidierende Physiker Frédéric Joliot-Curie), doch genießt der „weltbekannte französische Schriftsteller“ ${ }^{82}$ besonderen Status: „Der Kongreß war sich der Auszeichnung wohl bewußt, die ihm diese bemerkenswerte Begegnung verlieh. Die übrigen Delegierten waren beklatscht worden, pflichteifrig und in Maßen; Sartre wurde gefeiert. “83 Kommentare zum Kongress, in diesem Fall veröffentlicht in der deutschen Wochenzeitung Die Zeit, finden sich nur in internationalen Periodika. Obwohl unter den 178 JournalistInnen aus 30 Ländern wohlvertreten im Konzerthaus, halten die (nicht-kommunistischen) österreichischen jeden Kommentar vor ihrem Lesepublikum zurück. In Anbetracht der sonstigen Berichterstattung zu Sartre titelt das von Ernst Fischer, Bruno Frei und Viktor Matejka herausgegebene kommunistisch orientierte Tagebuch am 8. November 1952 in großen roten Lettern „Warum wird er jetzt totgeschwiegen?“:

Bisher hat jede noch so geringfügige Aeußerung Sartres im französischen und hernach im ganzen westlichen Blätterwald einen Sturm der Diskussionen entfacht. Diesmal bleibt

79 Friedrich Torberg: Sartre oder Die ehrbare Koexistenz. Zur Wiener Affäre um die ,Schmutzigen Hände‘. In: FORVM 1 (1954), Nr. 10, S. 16-17, hier S. 16 f.

80 Sartre: Le Congrès de Vienne. In: Le Monde, 01.01.1953.

81 Sartre: Ce que j’ai vu à Vienne, c'est la Paix. In: Les Lettres françaises, 01.-08.01.1953.

82 o. V.: Völkerkongreß für den Frieden, S. 5.

83 Steffen: Pilgrim des „Friedens“. In: Die Zeit, 25.12.1952. 
das Wasserglas der freien Weltmeinung unbewegt. Jean-Paul Sartre wird zum erstenmal unisono totgeschwiegen. ${ }^{84}$

\section{Nachdem das höchstgeschätzte Prinzip der Wien zu drei Vierteln besetzenden demokratischen Armeen („armées des démocraties bourgeoises“) die Pressefrei- heit sei, staunt auch Sartre selbst:}

Es gab da Dutzende von Wissenschaftlern, Politikern, Künstlern, die zu empfangen Wien bei anderer Gelegenheit stolz gewesen wäre; es gab da diese ganze bunte Mischung der Trachten und Sprachen. Kein Wort davon: nicht die kleinste Zeile in einer Zeitung. Der kleine Wiener Angestellte, der ein sozialdemokratisches Blatt liest und der in einem Außenbezirk wohnt, hat völlig in Unkenntnis über die Existenz des Kongresses bleiben können. ${ }^{85}$

(Il y avait par dizaines, par vingtaines, des savants, des hommes politiques, des artistes que Vienne à d'autres heures eût été fière de recevoir; il y avait l'ensemble le plus pittoresque de costumes et de langues. Pas un mot: pas la plus petite ligne dans un journal. Le petit employé viennois qui lit une feuille sociale-démocrate et qui habite un quartier périphérique a pu totalement ignorer l'existence du Congrès.) $)^{86}$

84 o. V.: Sartre. In: Tagebuch, 08.11.1952. Der Weltfriedensrat hatte bereits im November 1951 eine Tagung in Wien abgehalten, von der man annahm, sie würde „Widerhall finden von Paris bis Peking, von Stockholm bis Sidney“ (TB: Die geistige Elite der Welt trifft sich in Wien. In: Tagebuch, 27.10.1951), doch muss das Tagebuch schon bei dieser Gelegenheit vorwurfsvoll feststellen: „Die sonst so laute Regierungspresse hat wie ein Massengrab geschwiegen“ (10.11.1951). Auch die französischen Alliierten halten sich zurück, was durch Publikumsinterventionen bei einer Veranstaltung zum Existentialismus jedoch nicht ganz gelingt: „Jean-Paul Sartre wurde, das ist ein Verdienst der Wiener Urania und ihres Direktors Wolfgang Speiser, vergangene Woche in der Wiener Lesegemeinde diskutiert. Armand Jacob, der Leiter des französischen Informationsdienstes, gab eine in französischer Clarté und Präzision brillierende Darstellung des philosophischen und literarischen Werkes Sartres, die er, wechselseitig, auseinanderzudeuten unternahm. Sartres sensationelle Stellungnahme für die Weltfriedensbewegung [...] wurde erst in der sehr gespannten Diskussion erörtert. Sartres Wiener Bewunderer waren bloß fassungslos und aufs peinlichste berührt - nun; das ist schon etwas. [...] Sie verdächtigen sogar, unkontrolliert, das TB, die Aeußerungen Sartres tendenziös übersetzt und ausgewählt zu haben - das ist schon mehr. Es zeigt, wie perplex sie sind. Armand Jacob allerdings bestätigte, daß er die Uebersetzung und Auswahl kontrolliert und einwandfrei gefunden habe. TB wird den Erschrockenen mit weiterem unverfälschtem Sartre aufwarten.“ o. V.: Jean-Paul Sartre. In: Tagebuch, 22.11.1952.

85 Jean-Paul Sartre: Was ich in Wien gesehen habe, ist der Frieden. In: Sartre: Krieg im Frieden 2. Reden, Polemiken, Stellungnahmen 1952-1956. Hg. von Traugott König und Dietrich Hoß, übersetzt von Abelle Christaller, Dietrich Hoß, Traugott König und Eva Moldenhauer. (Gesammelte Werke in Einzelausgaben, Politische Schriften 3,2.) Reinbek 1982, S. 60-72, hier S. 65 (Hervorhebung im Oritinal).

86 Sartre: Ce que j'ai vu à Vienne, c'est la Paix. In: Les Lettres françaises, 01.-08.01.1953 (Hervorhebung im Oritinal).Dass der Kongress durchaus auch von Außenstehenden zur Kenntnis 
Es handelt sich hierbei nicht zufällig um einhellige Ignoranz, sondern um eine geschlossen befolgte Doppelmaßnahme aus „Diffamierung und Boykott“87. Die Regierung - eine in ihrem Antikommunismus als „einigendes Band“88 verbundene Große Koalition aus ÖVP (Österreichische Volkspartei) und SPÖ (Sozialistische Partei Österreichs) - hält die Medien via Mitteilungen des Bundespressedienstes zum Schweigen über den als reine Propagandaveranstaltung ausgegebenen Kongress an. ${ }^{89}$ Er wird im Vorfeld diskreditiert und danach geflissentlich übersehen, ganz im Einklang mit dem „United States View on Treating the Congress“:

During the first phase American information facilities will be exerted to de-bunk the Congress as sterile, hypocritical, a typical Communist effort designed to advance Soviet imperialist aims. The Congress will be dubbed ,schwindelfriedenskonferenz'. Great care will be taken not to overdo denunciation; the tone adopted will be cool and ironical. [...] During the sessions of the Congress American news facilities will completely ignore it. [...] Plans for action after the Congress are still fluid. If any of the Communist themes promoted at the Congress prove to have made any impression on the Austrian public, American information services will concentrate on exposing their falsity. ${ }^{90}$

Der letzte Schritt erweist sich als gar nicht nötig, vielmehr rühmen sich die österreichischen Medien des Erfolges ihrer Zensur-Bemühungen. Die bürgerlich-liberale

genommen wird, legen in späteren Jahren beiläufige Bemerkungen nahe, wie jene Fischls in Idealismus, Realismus und Existentialismus der Gegenwart, S. 312, dass Sartre seinerzeit „eine vielbeachtete Rede“ gehalten habe.

87 Mugrauer: Eine „rein kommunistische Angelegenheit“?, S. 131. Als Nebenmaßnahmen nennt Evelyn Deutsch-Schreiner in ihrer Untersuchung Theater im „Wiederaufbau“. Zur Kulturpolitik im österreichischen Parteien- und Verbändestaat (Wien 2001, S. 144) eine Reihe von „Bosheiten der österreichischen Bürokratie“: Einreiseschwierigkeiten für Delegierte, Probleme bei der Anmietung von Veranstaltungsräumen und Absagen bereits gebuchter Konzerte der Wiener Philharmoniker.

88 Dvořak: Thesen zur soziokulturellen Entwicklung in Österreich 1933 bis 1955, S. 32. Da sich Sartre die Verbindung linker Kräfte wünscht, erzürnt ihn insbesondere, dass die SozialdemokratInnen, statt über den Kongress zu berichten, nur kritische Zettel in die Hotelzimmer der Delegierten schicken lassen. In der Tat schweigt etwa die Arbeiter-Zeitung, in der der aus der englischen Emigration zurückgekehrte Oscar Pollak ansonsten alle „Irrtümer, Mißbräuche und Schikanen der Alliierten“ (Sperber: Bis man mir Scherben auf die Augen legt, S. 260) verlässlich aufdeckt und sich besonders sensibel in Zensurdingen zeigt, zumindest wenn sie ,von den Russen“ ausgehen (O. P.: Die Zensur. In: Arbeiter-Zeitung, 30.08.1950).

89 Cf. Ministerratsprotokoll 311/1 vom 04.11.1952. Cf. Viktor Matejka: Friedensfreunde sprechen menschlich. In: Tagebuch, 22.11.1952. Cf. auch Friedrich Heer: Die Provokation des Friedens. In: Die Oesterreichische Furche, 15.11.1952.

90 North Atlantic Council: NATO Secret Document (AC/24-D/16), S. 8. 
Tageszeitung Die Presse verkündet am 21. Dezember 1952, die Bevölkerung habe den „mit viel Geld und Lärm aufgezogene[n] sogenannte[n] Völker- und Friedenskongress“ ignoriert, während „die Welt mit einer Flut von Meldungen darüber überschwemmt wurde“"91. Am selben Tag informiert die New York Times ihre LeserInnen über die in Wien gerade noch abgewendete Gefahr: Der Kongress sollte nicht nur den „people of Soviet Russia and its satellites“ imponieren, sondern auch ,all those Western peoples - and their number is growing - who can be tempted by vanity, chauvinism, tender-mindedness or honest confusion to play the Cominform game“"92 . Die Menschen wären durchaus am Kongress interessiert gewesen, hätten sie davon gewusst, meint Sartre, und macht die mangelnde Berichterstattung auch für die bescheidene Teilnahme an der Friedensdemonstration verantwortlich. Der britische Journalist Mark Arnold-Forster hingegen stuft den Enthusiasmus der 7000 Personen, die sich wohlerzogen, „with a sort of sceptical lethargy“, um den Ring bewegen, als nicht ausbaufähig ein: „The Viennese [...] cannot be persuaded to demonstrate with vigour in favour of anything that seems to favour Russia, a country where, so far as they know, 1,900 Austrians are still held prisoner."93

Nach der Befreiung durch die Rote Armee, die nicht selten „mit brachialer Gewalt vorging“94, wachsen in Österreich vorhandene antikommunistische Ressentiments stark an: Bis Ende 1952 hat sich die Haltung der auf die Rückkehr der Kriegsgefangenen hoffenden Bevölkerung gegenüber der Sowjetunion von negativ zu feindlich gewandelt, Oscar Pollak spricht davon, dass „fünfundneunzig Prozent“ der ÖsterreicherInnen diesem Regime gegenüber „Angst und Abscheu“95 empfinden. Anders als in Frankreich, wo die Parti Communiste zunächst einen zentralen Platz in der intellektuellen Debatte (,une place centrale dans le débat intellectuel“96) innehat (bei der Parlamentswahl im Oktober 1945 erhält die

91 o. V.: „Völkerkongreß“ bleibt unter sich. In: Die Presse, 21.12.1952.

92 John MacCormac: Peace Congress in Vienna Runs True to Party Line. In: The New York Times, 21.12.1952.

93 Mark Arnold-Forster: Peace Doves in Vienna. In: The Spectator, 19.12.1952. Im Zusammenhang mit dem Völkerkongress, „der angeblich für den Weltfrieden werben will“, macht Die Presse (-the.: Völkerfrieden und Stacheldraht, 06.12.1952) nur auf einen „Schweigemarsch der Frauen und Mütter“ für die Rückkehr der Kriegsgefangenen aufmerksam, ebenso auf Zwischenfälle an tschechisch-niederösterreichischen Grenzzäunen, in denen flüchtende TschechInnen verwundet hängenblieben und von Spitälern direkt den russischen Besatzungsbehörden ausgeliefert würden.

94 Kroll: Kommunistische Intellektuelle in Westeuropa, S. 637.

95 O. P.: Die Zensur. In: Arbeiter-Zeitung, 30.08.1950.

96 Dugast: La Situation culturelle de la France après 1945, S. 312. 
PCF 26,1\% der Stimmen, verglichen mit 5,4\% für die nicht in den Kernschichten der Wiener ArbeiterInnenschaft verankerte KPÖ bei den österreichischen Nationalratswahlen im September 1945), ${ }^{97}$ bevorzugt das geographisch zwischen den Fronten gelegene Österreich klar den Westen, so Rathkolb:

Nach dem Zweiten Weltkrieg war die Abgrenzung vom kommunistischen System der Nachbarstaaten für Österreich ein wesentliches Element, den Glauben an die Kleinstaatlichkeit zu stärken. Geschickt wurde das Argument einer angeblichen ständigen kommunistischen Bedrohung von innen und außen vor allem gegenüber den USA ausgespielt. ${ }^{98}$

Aus amerikanischer Sicht am stärksten vom Kommunismus bedroht, erhält das Land hohe Marshallplan-Zuwendungen. ${ }^{99}$ Es zählt, ganz die von Hebbel besungene kleine Welt, in der die große ihre Probe hält, zu den für das komplexe Verhandlungsgeschehen zwischen den Blöcken wichtigsten Staaten. Zum Zeitpunkt, als der Völkerkongress zum Schauplatz des kulturellen Kalten Kriegs wird, herrscht, obwohl die Truppenstärke der Sowjetbesatzung die der anderen Armeen übersteigt, eine weitgehende Marginalisierung der KPÖ und ,eine politische und gesellschaftliche Isolation“ der kommunistischen Intellektuellen vor, deren demokratische Anliegen Kroll zufolge „schnell als Camouflage einer diktatorischen Bewegung “100 gelten. Diese Situation erklärt, warum eine unrealistisch hohe Zahl an Unterschriften zugunsten des Völkerkongresses im Nationalrat, wo die Veranstaltung ohnedies ein „besonderes Kapitel“ darstellt, am 20. November $1952 \mathrm{zu}$ einer tumultuösen Debatte führt: Innenminister Oskar Helmer (SPÖ) meint, die Unterschriften müssten von den KommunistInnen erlistet oder erzwungen worden sein, was „energischen Protest“ verlange, während der Abgeordnete Ernst Fischer (KPÖ) beanstandet, dass die für den Frieden einstehenden Intellektuellen, ProfessorInnen und KünstlerInnen Drohungen seitens der Regierungsparteien ausgesetzt seien. ${ }^{101}$ In der Tat konnten nicht-kommunistische Prominente, die sich von der österreichischen Sektion

97 Die KPÖ bildet zusammen mit der ÖVP und der SPÖ ab 27.04.1945 die provisorische Regierung unter Kanzler Karl Renner. Die Dreiparteienregierung bleibt auch unter Leopold Figl nach den 1. Wahlen im November 1945 bestehen, im Jahr 1947 wird die KPÖ Oppositionspartei. 98 Oliver Rathkolb: Die paradoxe Republik. Österreich 1945 bis 2005. Wien 2005, S. 31.

99 Cf. Günter Bischof: Austria in the First Cold War, 1945-1955. The Leverage of the Weak. Basingstoke 1999, S. 102. Cf. zum diesbezüglichen Sonderstatus Österreichs auch Maximilian Graf und Agnes Meisinger (Hg.): Österreich im Kalten Krieg. Neue Forschungen im internationalen Kontext. (Zeitgeschichte im Kontext 11.) Göttingen 2016.

100 Kroll: Kommunistische Intellektuelle in Westeuropa, S. 312, 637.

101 Cf. Nationalrat der Republik Österreich: 103. Sitzung des Nationalrates der Republik Österreich - VI. Gesetzgebungsperiode - 20.11.1952, S. 4130, 4138. www.parlament.gv.at (einges. 09.01.2019). 
des Weltfriedensrats zu Unterschriften hatten animieren lassen, mit „verbalen Diffamierungen und Verfolgungen“ rechnen, wie Deutsch-Schreiner ausführt:

Hatte das antikommunistische Lager Unterschriften von KünstlerInnen und Friedensappelle bis 1950 noch toleriert, so wurden KünstlerInnen nun ,gewarnt‘ und als ,Dummköpfe' oder ,Lumpen' diffamiert, sollten sie weiterhin Kontakt zu Kommunisten haben. Unmißverständlich wurde klargemacht, daß diejenigen, die sich für den ,Völkerkongreß für den Frieden` engagierten, kein Engagement im anderen Lager finden würden. ${ }^{102}$

Der Kongress selbst lässt entsprechend die Partizipation prokommunistischer Intellektueller vermissen; solche, die sich zuvor zur Zusammenarbeit mit der KPÖ bereitfanden, wie PEN-Präsident Franz Theodor Csokor und Alexander SacherMasoch, machte „großer Druck ${ }^{\text {(103 }}$ zu Beginn des Jahrzehnts abtrünnig. Den Umgang mit kommunistischen KünstlerInnen verdeutlicht kurz darauf der ab 1953 von den etablierten Wiener Theatern über zehn Jahre aufrechterhaltene Boykott der Stücke Bertolt Brechts (der zum Kongress 1952 ebenfalls eine Rede über die drohenden Kriege, „gegen welche die vergangenen wie armselige Versuche sind“104, beigetragen hatte). Um dessen als Ost-Propaganda aufgefasste Dramen entsteht eine „kulturelle Eiszeit, betonte Intoleranz und ideologische Militarisierung“105 der Theaterwelt; Torberg und Weigel bilden die Vorhut gegen Brechts „Kampf gegen uns und unsere Freiheit“"106 . Der Freiheits-Diskurs der USA, von den KommunistInnen als imperialistische Bevormundung aufgefasst, gerät bald in einen „Krieg der Worte“ mit dem kommunistischen „Kampfbegriff“"107 Frieden;

102 Deutsch-Schreiner: Theater im „Wiederaufbau“, S. 144.

103 Mugrauer: Eine „rein kommunistische Angelegenheit“?, S. 139.

104 Bertolt Brecht: Zum Völkerkongreß für den Frieden. In: Brecht: Schriften zur Politik und Gesellschaft. 1919-1956. Frankfurt am Main 1974, S. 322-323, hier S. 323. [Zuerst in: Neues Deutschland, 29.11.1952.]

105 Rathkolb: Die Entwicklung der US-Besatzungskulturpolitik, S. 41.

106 Hans Weigel: Die Lust am Untergang. In: neue generation 10 (1960), Nr. 2, S. 16.

107 Kraus: Kultura, S. 116, 92. Cf. auch Stefan Maurer, Doris Neumann-Rieser und Günther Stocker: Diskurse des Kalten Krieges. Eine andere österreichische Nachkriegsliteratur. (Literaturgeschichte in Studien und Quellen 29.) Wien, Köln, Weimar 2017, S. 435. Unmut zieht Karl Paryla auf sich, als er im Wiener Neuen Theater in der Scala zur „Erreichung des weltpolitischen Friedens im Sinne der Sowjetunion“ (Deutsch-Schreiner: Theater im „Wiederaufbau“, S. 143) Grillparzers Der Traum ein Leben 1952 ein wenig ,strafft': Lediglich „Eines nur ist Glück hinieden, / Eines nur: der Frieden“ bleibt übrig von: „Breit es aus mit deinen Strahlen, / Senk es tief in jede Brust: / Eines nur ist Glück hinieden, / Eins: des Innern stiller Frieden, / Und die schuldbefreite Brust. / Und die Größe ist gefährlich, / Und der Ruhm ein leeres Spiel; / Was er gibt, sind nichtge Schatten, / Was er nimmt, es ist so viel.“ Franz Grillparzer: Dramen 18281851. Hg. von Helmut Bachmaier. (Werke in sechs Bänden, 3.) Frankfurt am Main 1987, S. 191. 
es treten „pauschale Reizwörter“108 an die Stelle von Argumenten. So klagt die gegen den „Weltkommunismus“ gerichtete Zeitschrift Kontinente, dass ,aus der Tradition der freien Welt“ herausgewachsene Worte wie Frieden „zu leeren Schlagworten“ herabgesetzt würden: „Der Sinn dieser Worte ging verloren, und die Aufgabe der politischen Aufklärungsarbeit besteht wohl darin, sie mit neuem Sinn zu erfüllen und dadurch für uns zurückzugewinnen."109 Ganz dieser Meinung ist man schon beim West-Berliner Treffen des „Kongresses für kulturelle Freiheit“ (CCF, 26. bis 30. Juni 1950), einer von der CIA finanzierten Kulturorganisation, welche Zeitschriften wie Der Monat, Preuves, FORVM und Encounter unterstützt und sich schon mit ihrem Namen im ,Krieg der Worte‘ klar positioniert. Zugehörige wie Manès Sperber, Arthur Koestler und Melvin J. Lasky äußern, „daß die Hauptursache der gegenwärtigen weltweiten Unsicherheit durch die Politik von Regierungen entsteht, die sich mit Worten zum Frieden bekennen“, nicht aber mit Taten:

Die Geschichte lehrt, daß man Kriege unter jedem beliebigen Schlagwort vorbereiten und führen kann, auch unter dem Schlagwort des Friedens. „Friedenskampagnen“, hinter denen kein Beweis eines echten Friedenswillens steht, gleichen dem Papiergeld einer ungedeckten Währung. Die Welt wird erst dann geistig gesunden und ihre Sicherheit wiederfinden, wenn dieses Falschgeld des Friedens nicht mehr für bare Münze genommen wird. ${ }^{110}$

Anfang der fünfziger Jahre ist die Westintegration Österreichs so weit fortgeschritten, dass der Kulturbetrieb auch ohne amerikanisches Zutun ganz auf Seiten des Antikommunismus steht, was das „Niederhalten [...] kritischer Intelligenz“111 einbegreift, so Dvořak. Die französische Besatzungsmacht muss in diesem Klima von ihrem ursprünglichen Plan abrücken, jede Polarisierung zu vermeiden, wie ihn De Broglie einst formuliert:

Österreich ist eine Wesenheit für sich und muß es bleiben. Es ist wie der Arm eines Wegweisers, der sich zwischen Ost und West verbindend ausstreckt; es ist dazu berufen, ein Land des Austausches der Ideen und Systeme zu sein, ein Gradmesser der Strömung zwischen zwei Zivilisationen. Alle Anstrengung der Westmächte, namentlich Frankreichs, ihren kulturellen Einfluß in diesem Lande zu vermehren, ist dazu angetan, das Gleichgewicht zu befestigen und dadurch die Beständigkeit des Friedens zu erhöhen. ${ }^{112}$

108 Norbert Frei: Die fünfziger Jahre im Spiegel von Schriftsteller-Autobiografien. In: Aspetsberger, Frei und Lengauer (Hg.): Literatur der Nachkriegszeit, S. 59-74, hier S. 63.

109 Die Redaktion: Unter uns gesagt. In: Kontinente 8 (1955), Nr. 6, o. S.

110 [Sperber, Koestler, Lasky, Burnham, Schlesinger und Hook:] Manifest. In: Der Monat, 1950, Nr. 22/23, S. 483-484, hier S. 483.

111 Dvořak: Thesen zur soziokulturellen Entwicklung in Österreich 1933 bis 1955, S. 32.

112 De Broglie: Von der Seine zu Inn und Etsch, S. 174. 
(L'Autriche est et doit demeurer une entité. Jalon, bras tendu entre l'Est et l'Ouest, elle est appelée à être un terrain d'échanges d'idées et de systèmes, un niveau d'eau entre deux civilisations. Tout effort des puissances occidentales et spécialement de la France, pour accroître leur apport culturel dans ce pays est destiné à consolider l'équilibre et par conséquent à augmenter les chances de la paix.) $)^{113}$

Kommunistische Intellektuelle und PolitikerInnen - so der aus dem Moskauer Exil zurückgekehrte Ernst Fischer, Staatssekretär für Volksaufklärung, Unterricht, Erziehung und Kultusangelegenheiten, oder Kulturstadtrat Viktor Matejka - waren zunächst privilegierte PartnerInnen im Kampf gegen den nationalsozialistischen Einfluss. Zwar gilt Hochkommissar Béthouart als Gaullist und das zivile und militärische Besatzungspersonal überwiegend als „weder kommunistisch noch sozialistisch [...], sondern politisch indifferent“, doch glaubt man sich laut Sperber durch die Zusammenarbeit mit den KommunistInnen „gegen Angriffe der sehr aggressiven linken Presse am wirksamsten zu schützen“"114. Bis 1950 wendet sich das Blatt, Béthouart verkündet in Alpbach: „Wir kämpfen und werden für die menschliche Freiheit kämpfen, gegen die neuen Formen der Sklaverei und Knechtschaft, die der kommunistische Totalitarismus eingeführt hat.“115 Entsprechend halten die französischen Alliierten Distanz, als Sartre 1952 und 1954 in der Funktion des prokommunistischen Wegbegleiters nach Österreich kommt. ${ }^{116}$

Sartre bereitet 1952 nicht sein kommunistisches, sondern sein antikommunistisches Image Sorge: Wohlwissend, dass das Theater Hauptumschlagplatz seiner Ideen ist, insbesondere in Ländern, in denen Übersetzungen mit mehrjähriger Verzögerung erscheinen, lässt er eine für den Zeitpunkt des Friedenskongresses geplante Wiener Inszenierung des Stücks Les Mains sales absagen, um eine Instrumentalisierung des Inhalts zu verhindern. Das 1948 uraufgeführte, im südosteuropäischen ,Illyrien“ spielende Polit-Drama konfrontiert einen arrivierten Pragmatiker (Hoederer) mit einem jungen Idealisten (Hugo), der zum Werkzeug seiner GenossInnen wird. Hoederers Kompromissbereitschaft gegenüber gegnerischen Gruppierungen wirft die im besetzten Frankreich virulent gewordene Frage auf, ob der Zweck die Mittel rechtfertigt (damals

113 De Broglie: Souvenirs français dans le Tyrol, S. 174 (Hervorhebung im Oritinal).

114 Sperber: Bis man mir Scherben auf die Augen legt, S. 259.

115 o. V.: Rede zur Eröffnung des Alpacher [!] College, gehalten von Armeegeneral Bethouart, Hochkommissar der Französischen Republik in Österreich. In: Geistiges Frankreich, 21.08.1950.

116 Auch Porpaczy erwähnt, „daß in Wien das Bild Sartres weder durch die öffentlichen Vertreter Frankreichs noch durch eine französisch-österreichische Diskussionsrunde, bei der Sartre Gelegenheit gehabt hätte, Stellung zu nehmen, zurechtgerückt wurde. Die gesamte Angelegenheit wurde ausschließlich in Form einer ,Schlammschlacht" der österreichischen Presse ausgetragen.“ Porpaczy: Frankreich - Österreich, S. 229. 
konkret, ob nur der Untergrundkampf in der Résistance zulässig sei oder auch die Zusammenarbeit mit kollaborierenden Verlagen und Theatern, um einem größeren Publikum verdeckte Widerstandsbotschaften zu vermitteln; cf. Kap. 3.2). Hoederer legt Hugos orthodoxen Marxismus als unaufrichtig bloß, er liebe nicht die eigentlichen Menschen, sondern nur Prinzipien (,[t]u n’aimes pas les hommes. Tu n'aimes que les principes“'117). Der Konflikt der von Selbstzweifeln geplagten Figur Hugo liegt darin, immer ein Intellektueller zu sein, der nicht mit seinen Händen arbeitet (,un intellectuel, un type qui ne travaille pas de ses mains“118). Bei seiner Wandlung vom Wort- zum Tatmenschen erfährt er jedoch „die Unmöglichkeit, im politischen Engagement innere Reinheit zu bewahren" ${ }^{119}$ beziehungsweise saubere Hände. Hugos Bereitschaft, innerhalb seiner Partei mit einem Auftragsmord zum direkten Handeln (,action directe“(120) überzugehen, fällt schließlich der Parteichef Hoederer zum Opfer.

Insbesondere durch die Thematisierung des politischen Mordes, gesehen als eine Konstante bei den Kämpfen innerhalb der P. C. („une constante de la lutte à l'intérieur du P.C.“121), wird das Stück als anti-kommunistisch aufgefasst, glaubt Sartre. Beauvoir ergänzt, das Stück erscheine antikommunistisch, weil die Öffentlichkeit Hugo recht gebe; der Mord an Hoederer werde mit den der Kominform zugeschriebenen Verbrechen verglichen (,[1]a pièce sortait anticommuniste parce que le public donnait raison à Hugo. On assimila le meurtre d'Hoederer aux crimes qu’on imputait au Kominform“122). Sartre selbst weist Hoederer 1964 rückblickend als positiven Helden aus, mit dem er sich identifizieren könne, das Stück sei, wenn überhaupt, ein Wegbegleiter-Werk (,une œuvre de ,compagnon

117 Jean-Paul Sartre: Les Mains sales. In: Sartre: Théâtre complet, S. 245-354, hier S. 332. Dies ist zugleich das Echo einer Szene aus La Nausée, in der der Held Roquentin seinem Bekannten, dem sogenannten Autodidakten, dessen abstrakten Humanismus vorhält. Der Autodidakt liebe die Menschen nicht wirklich: „,Das sind nur Symbole für Sie. Sie lassen sich keineswegs von ihnen rühren; Sie lassen sich von der Jugend des Menschen rühren, von der Liebe von Mann und Frau, von der menschlichen Stimme.““ („Ce ne sont que des symboles, pour vous. Ce n'est pas du tout sur eux que vous êtes en train de vous attendrir; vous vous attendrissez sur la Jeunesse de l'Homme, sur l'Amour de l'Homme et de la Femme, sur la Voix humaine.") Sartre: Der Ekel, S. 137. (Sartre: La Nausée, S. 170.)

118 Sartre: Les Mains sales, S. 332.

119 Améry: In die Welt geworfen, S. 197. Cf. Jean-Paul Sartre: Entretien avec Guy Dornand. In: Sartre: Théâtre complet, S. 363. [Zuerst in: Franc-Tireur, 25.03.1948.]

120 Sartre: Les Mains sales, S. 262.

121 Jean-Paul Sartre: Entretien avec Paolo Caruso. In: Sartre: Théâtre complet, S. 367. [Zuerst: Postface à l'édition italienne „Le mani sporche“, 1964.]

122 Beauvoir: La Force des choses, Bd. 1, S. 212. 
de route“(123), an sich aber nicht politisch, nur von Politik handelnd. Er folgt dahingehend seinem literarischen Prinzip des nicht erklären oder überzeugen wollenden Aufzeigens (cf. Kap. 6.4); sich auf keine Seite schlagend, wolle er mit seinem Theater Probleme aufwerfen, nicht lösen (,[j]e ne prends pas parti. Une bonne pièce de théâtre doit poser les problèmes et non les résoudre“124).

Die Reaktionen auf Les Mains sales stellen Sartres rezeptionslastiges Ideal allerdings von Anfang an auf die Probe, indem sie ihm die von seinen eigenen Absichten gänzlich unberührt bleibende Macht der LeserInnen und KritikerInnen vor Augen führt. So bezieht Sartres späterer Freund Ilya Ehrenburg im Sinne der sowjetischen Haltung Position gegen das Drama, das - weder von einem perplexen Philosophen noch von einem aufsässigen Utopisten geschrieben - ein reiflich überlegtes, antikommunistisches und -sowjetisches Pamphlet sei (,[e]lle est écrite non pas par un philosophe perplexe ni par un utopiste révolté, c'est un pamphlet anticommuniste et antisoviétique mûrement réfléchi“(125). In dem Klima von Misstrauen und Missverständnissen („climat de méfiance et de malentendus“), das Ende der vierziger Jahre in Frankreich herrsche, gelte alles nicht ausdrücklich Prokommunistische automatisch als antikommunistisch, gerade wenn es von Sartre, der bevorzugten Zielscheibe („cible privilégiée“126) der KommunistInnen, stamme. Er selbst formuliert in Qu'est-ce que la littérature?, dass man das Wort ,faschistisch“ in dieser Zeit allen EuropäerInnen zudenke, die nicht kommunistisch wählten (,le mot de fasciste, en Europe, tout citoyen européen qui ne vote pas pour les communistes“127). Die Presse folgt der Entweder-oderLogik und überhäuft Sartre laut Beauvoir verbal mit Blumen, nachdem das kom-

123 Sartre: Entretien avec Paolo Caruso, S. 367. Cf. auch Gabriel Marcels Stellungnahme in Les Nouvelles littéraires, 13.05.1948: „Wenn das Stück groß ist, dann gerade deshalb, weil sein Wert in ihm selbst liegt, außerhalb jedes Systembezugs. Es gibt übrigens keinen schwerwiegenderen Fehler, als in ihm ein antikommunistisches Stück zu sehen, es ist keins, natürlich auch kein prokommunistisches, in Wirklichkeit ist es kein Stück über den Kommunismus.“ [Übers. d. Verf.] („Si la pièce est grande, c'est que justement elle vaut par elle-même en dehors de toute référence à un système. Il n'y a d'ailleurs pas de plus lourde erreur que de voir en elle une pièce anticommuniste, elle n'est, évidemment, pas non plus procommuniste, en réalité ce n'est pas une pièce sur le communisme.“) Cf. Ingrid Galster und Sandra Teroni: Dossier de réception. In: Sartre: Théâtre complet, S. 1363-1390, hier S. 1389.

124 Jean-Paul Sartre: Entretien avec René Guilly. In: Sartre: Théâtre complet, S. 365. [Zuerst in: Combat, 31.03.1948.]

125 Ilya Ehrenbourg: Contre le mensonge politique. Faulkner et Sartre vus par un écrivain soviétique. Les Mains sales. In: Les Lettres Françaises, 10.02.1949. Cf. Galster und Teroni: Dossier de réception, S. 1390.

126 Sandra Teroni: Les Mains sales. Notice. In: Sartre: Théâtre complet, S. 1372-1387, hier S. 1374.

127 Sartre: Qu'est-ce que la littérature?, S. 281 (Hervorhebung im Oritinal). 
munistische Urteil zu Les Mains sales schlecht ausfällt. ${ }^{128}$ Seit der Premiere am 2. April 1948 im Théâtre Antoine viel Aufsehen erregend, wird es schließlich zum Star-Stück des Jahres („la pièce vedette de l'année“129). Der antikommunistische Ruf verfestigt sich in weiterer Folge durch die Rezeption in den USA, wo das als Red Gloves angekündigte Stück schon vor der Premiere reichlich „falsifying publicity“130 umgibt und von Sartre für derart tendenziös gehalten wird, dass er im Februar 1949 rechtliche Schritte gegen die Aufführung einleitet.

Die Bulletin-EmpfängerInnen des französischen Dokumentationszentrums erfahren am 26. April 1948, dass der Erfolg des Stücks außerhalb der kommunistischen Kritik „unbestritten“ sei, es herrsche Einigkeit über „die verblüffende Virtuosität der Technik“ Sartres, nirgends finde man „einen gezierten Satz oder theatralische Phrasen, nur direkte, kräftige Worte“, überhaupt sei das Stück „wie aus dem Leben gegriffen“ und versetze die ZuschauerInnen „in atemlose Aufregung،131. Bis sich ein solcher Effekt in Österreich einzustellen vermag, sollen allerdings noch sechs Jahre vergehen. Einen kleinen Eindruck vermittelt zuvor die Zeitschrift Komödie, die schon Sartres Die Fliegen-Vorrede abgedruckt hatte (cf. Kap. 3.2), und nun die ersten vier Szenen vom sechsten Bild der Schmutzigen Hände - die finale Konfrontation zwischen Hugo und Hoederer - in der Übersetzung von Milo Dor bringt. ${ }^{132}$ Danach steht über der österreichischen Aufführungsgeschichte „ein ungünstiger Stern“"133, beginnend mit dem Scheitern einer Volkstheater-Inszenierung im Dezember 1950 durch eine laut Hans Weigel „charakteristische Affäre“:

Das Volkstheater hatte es angenommen, angekündigt und besetzt, als einige Schauspieler, wie zu erwarten, Drohbriefe bekamen. Die Schauspieler wandten sich daraufhin mit einem platonischen Protest an die Direktion, um von ihr zum Spielen der Rollen auf Grund der Verträge angehalten zu werden und sich notfalls auf diesen „Zwang“ berufen zu können. Die Direktion wandte sich ihrerseits an ihre Vorgesetzten, die Gewerkschaften, um durch sie gedeckt zu werden. Diese aber bekamen Angst vor der eigenen Courage

128 Beauvoir: La Force des choses, Bd. 1, S. 212.

129 Teroni: Les Mains sales. Notice, S. 1372.

130 Robert Greer Cohn: Scenes From Les Mains Sales. In: Yale French Studies 1948, Nr. 1, S. 3-20, hier S. 3.

131 o. V.: Les Mains Sales (Schmutzige Hände) von Jean-Paul Sartre. In: Kulturelles, 26.04.1948.

132 Cf. Auszüge aus Schmutzige Hände, 6. Bild, 1.-4. Szene. Deutsch von Milo Dor. In: Komödie 3 (1948-49), Nr. 2, S. 41-47.

133 o. V.: Makabres Intermezzo. In: Die Presse, 24.09.1954. 
und setzten unter Bruch eines geschlossenen Vertrages das Stück ab. So siegte im amerikanischen Sektor Wiens der kommunistische Druck über sozialistische Funktionäre und ein antikommunistisches Stück. ${ }^{134}$

Was geschehen war, ist für die Arbeiter-Zeitung, das auflagenstarke „Zentralorgan der Sozialistischen Partei Österreichs“, weit weniger klar:

Gerüchte tauchten auf; der oder jener Schauspieler habe eine Warnung erhalten: wenn er in diesem Stück mitspiele ... er werde schon sehen ... in Deutschland sei auch ... die Russen würden ... Kurz und schlecht: auf allerlei Umwegen, direkt und indirekt, haben sich die meisten Schauspieler des Volkstheaters geweigert, bei dieser Aufführung mitzuwirken. So weit ist es in Wien mit der kulturellen Freiheit gekommen! ${ }^{135}$

Die von der Arbeiter-Zeitung geäußerten Verdächtigungen und ihr Auffordern des Ensembles, Zivilcourage zu zeigen, empfindet die marxistisch ausgerichtete Zeitschrift Tagebuch als „Kommunistenhetze“136. Im kulturpolitischen „Kreuzfeuer“, wie Michael Kraus die Presse-Interaktionen in dieser Causa bezeichnet, steht der Arbeiter-Zeitung - unter Chefredakteur Oscar Pollak zunehmend „Speerspitze des österreichischen Antikommunismus“137- auch die von der sowjetischen Besatzungsmacht dirigierte Österreichische Zeitung entgegen, die von Erpressung spricht, allerdings in der Gewissheit, dass das Stück beim fortschrittlichen Publikum ohnehin „keinerlei Aussicht auf Erfolg“138 habe. Die Erstaufführung von Schmutzige Hände (Regie: Ludwig Andersen) findet im November 1951 in den Grazer Kammerspielen in der britisch verwalteten Steiermark statt, wo sich laut der Österreichischen Zeitung „ein devoter Theaterleiter fand, der bereit war, sein Institut mit diesem Gesudel in Mißkredit zu bringen“139. Wenn auch als eine jener Ausnahmen im Schauspielangebot, die „die

134 Weigel: Brief aus Wien, S. 181. Da nach 1950 beispielsweise ein Auftritt bei der „Russischen Stunde“ der RAVAG (der 1924 gegründeten und nach Ende des Zweiten Weltkriegs von prosowjetischen Kräften geführten Rundfunkgesellschaft) bedeutete, nicht mehr beim amerikanischen Sender Rot-Weiß-Rot beschäftigt zu werden, haben die SchauspielerInnen durchaus Gründe, Vorsicht walten zu lassen. ,Schwarze Listen' stigmatisieren selbst solche, deren Namen sich in Glückwunschtelegrammen in prokommunistischen Periodika finden. Cf. Rathkolb: Die Entwicklung der US-Besatzungskulturpolitik, S. 40 f. Auf der anderen Seite kriminalisieren kommunistische Redaktionsmitglieder die SchauspielerInnen in Sartres Stücken als „Helfershelfer“ eines verbrecherischen Dramatikers. E. K.: Eine Verzerrung des Menschen. In: Österreichische Zeitung, 15.11.1947.

135 O. P.: „Schmutzige Hände“ und feige Herzen. In: Arbeiter-Zeitung, 15.12.1950.

136 Karl Paryla: Feig und frech. In: Tagebuch, 23.12.1950.

137 Kraus: Kultura, S. 154.

138 o. V.: Ein Anwalt der „Schmutzigen Hände“. In: Österreichische Zeitung, 16.12.1950.

139 o. V.: Ein Theaterskandal. In: Österreichische Zeitung, 30.11.1951. 
grundlegend konservative Haltung، ${ }^{140}$ des Grazer Hauses als Regel bestätigen, lässt sich dennoch mit Porpaczy fragen, ob man außerhalb der Einflusssphäre der französischen Besatzung nicht „letztlich direkter und ,ungehinderter an französische Avantgarde herantrat als das Publikum in Innsbruck oder Wien“141. Für die Arbeiter-Zeitung jedenfalls wird die „Beschämung unserer Theater, denen das in Graz Selbstverständliche für Wien zu gefährlich erscheint", nur durch eine erste, von der Bezirksorganisation der Sozialistischen Partei Fünfhaus (Regie: Max Pfeiler) veranstaltete Lesung des Stücks im Jänner 1952 gemildert; auch in diesem kleinen Maßstab zeige sich bereits, wie Sartre „mutig und entschlossen an die Gestaltung brennender Zeitfragen herangeht“: „Die Sache, die verhandelt wird, geht alle an, denn es geht um die stolze und einsame Freiheit des Menschen. Wer gegen dieses Stück polemisiert, macht sich verdächtig!“142 Binnen kurzer Zeit wird Les Mains sales in Wien zu einem Paradebeispiel für „den eminenten Stellvertretercharakter“143 von Kunst während des Kalten Kriegs.

Als der „Völkerkongress für den Frieden“ Ende 1952 naht, sieht Sartre sich gezwungen, gegen das zeitgleich am Theater am Parkring geplante „Problemstück“144 vorzugehen, das ihn zum „Aushängschild des militanten Antikommunismus“145 gemacht hat, aus kommunistischer Perspektive gar zu einem der

140 Johann Strutz: ... die Dichter dichten, die Maler malen und die Komponisten komponieren. Über die Kulturpolitik der Steiermark in den fünfziger Jahren. In: Aspetsberger, Frei und Lengauer (Hg.): Literatur der Nachkriegszeit, S. 139-154, hier S. 142. Cf. Johannes Feichtinger: Stimulierung zur Modernisierung. Die Aufnahme moderner französischer Kultur in Graz: ein regionales Beispiel für Kulturtransfer. In: Angerer und Le Rider (Hg.): Französisch-österreichische Kulturtransfers seit 1945, S. 137-150. Von den 110 Sartre-Inszenierungen, die die Datenbank theadok für den Zeitraum 1945 bis 2000 verzeichnet (Marschall et al.: 50 Jahre Theater in Österreich), entfallen 61 auf Wien, neun auf Salzburg, acht auf Klagenfurt, sieben auf Linz, fünf auf Graz, vier auf Bregenz, je zwei auf Steyr, Innsbruck, Leoben, St. Pölten und Amstetten, und je eine auf Villach, Eisenstadt, Wiener Neustadt und Wels.

141 Dies schreibt Porpaczy (Frankreich - Österreich, S. 224) in Bezug auf die positive Aufnahme von Hinter geschlossenen Türen in Graz. Ähnlich wird sich die Situation in Linz darstellen, wo das Stück Ende 1952 gespielt wird und „eine intensive, aber sachliche Diskussion ohne besonderen Aufruhr“ (S. 222) nach sich zieht, während sich in Wien die Polemik um Sartres Schmutzige Hände-Verbot durch seinen Völkerkongress-Auftritt zuspitzt.

142 Kahl: Leseaufführung von Jean-Paul Sartres ,Die schmutzigen Hände‘. In: Arbeiter-Zeitung, 23.01.1952.

143 Deutsch-Schreiner: Theater im „Wiederaufbau“, S. 145.

144 o. V.: Herr Sartre protestiert. In: Arbeiter-Zeitung, 24.09.54.

145 o. V.: Jean Paul Sartre in Wien. In: Der Abend, 12.12.1952. 
„reaktionärsten Autoren“ samt „imperialistische[r] Ideologie“146. Ansonsten großen Wert auf den Publikumsbeitrag legend, offenbart Sartres Verbot Bedenken, ob Literatur, der solcherart „ein Stempel aufgedrückt" ${ }^{\text {147 }}$ wurde, noch ein Appell an die Freiheit der Lesenden („un appel à la liberté du lecteur") sein könne, oder ob nicht vielmehr die von den Medien kreierten Rezeptionsklischees die LeserInnen ihrer Verantwortung enthöben, in jedem Falle konkret („en chaque cas concret“148) zu urteilen. Im Kontext des Kongresses bestätigt sich für Sartre jedenfalls, was er seit langem ahnt und bald ins Zentrum seines satirischen Stücks Nekrassov (UA 1955) stellen wird: dass die antikommunistische Presse einen lockeren Umgang mit der Wahrheit pflege und nun sogar systematische, absurde und schamlose Lügen („systématiques, absurdes, éhontés“"149) verbreite. So berichtet beispielsweise Le Monde vom Nicht-Erscheinen sichtbar beim Kongress anwesender Intellektueller, worauf die konservative Neue Wiener Tageszeitung am 17. Februar 1953 einen Artikel folgen lässt über Sartre, „der sich bekanntlich zum kommunistischen Friedenskongreß in Wien angesagt hatte, aber dann doch nicht erschienen ist“150. Die KP-nahe Boulevardzeitung Der Abend korrigiert: „Noch vor wenigen Tagen schrieb die gleichgeschaltete Presse, die die Gesinnungsänderung Sartres nicht wahr haben will, daß er die Teilnahme am Völkerkongreß abgesagt hat. Doch Sartre ist gekommen!“151 Falschmeldungen dieser Art haben die (pro)kommunistische Presse überzeugt, dass mit der geplanten Volkstheater-Aufführung im Dezember 1952 „offenkundig reaktionäre Kräfte eine Störaktion gegen den zu jener Zeit in Wien abgehaltenen Weltfriedenskongreß starten wollten“152. Auch Sartre hält das Datum für keinen Zufall:

[Es] scheint nach meiner Ansicht in den Rahmen von Scharmützeln des Kalten Krieges zu fallen. Ich desavouiere weder die ,Schmutzigen Hände“ noch irgendein anderes meiner Werke. Ich will aber nicht, daß man sich ihrer zu Propagandazwecken bedient [...]. Wenn

146 O. S.: Die Dramatik Sartres - eine Predigt des Menschenhasses. In: Österreichische Zeitung, 16.12.1950.

147 hs.: Viel Wasser um „Schmutzige Hände“. In: Neue Wiener Tageszeitung, 24.09.1954.

148 Sartre: Qu'est-ce que la littérature?, S. 103, 288.

149 Sartre: Ce que j'ai vu à Vienne, c'est la Paix. In: Les Lettres françaises, 01.-08.01.1953.

150 o. V.: o. T. [S. 8], in: Neue Wiener Tageszeitung, 17.02.1953.

151 o. V.: Jean Paul Sartre in Wien. In: Der Abend, 12.12.1952. Das Tagebuch druckt sicherheitshalber am 14.03.1953 neben den Text (o. V.: Erschienen oder nicht erschienen?) ein Beweisfoto von Sartre in Wien.

152 o. V.: Jean-Paul Sartre: Ich desavouiere die Aufführung. In: Österreichische Zeitung, 24.09.1954. 
Menschen aller Nationen und, wie ich hoffe, aller politischen Ansichten eine Bemühung unternehmen, sich zu verständigen, ist der Augenblick schlecht gewählt, gerade dort alte Angriffe wiederaufzunehmen ${ }^{153}$.

Der Leiter des betroffenen Theaters am Parkring, Erich Neuberg, ist sich keines Scharmützels bewusst, vielmehr habe er ,das Recht auf Sartres Stück im März 1952 erworben, in einem Augenblick, in dem kein Mensch ahnen konnte, daß der Autor jemals einem kommunistisch einberufenen Kongreß beiwohnen würde. Auf meiner Bühne wird keine Propaganda getrieben. ${ }^{154}$ Neuberg beharrt auf der für den 6. Dezember 1952 angesetzten und zeitaufwendig geprobten Premiere, um sein junges Haus (die „,beste und lebendigste Bühne der Stadt“155 laut Weigel) vor dem finanziellen Ruin $\mathrm{zu}$ retten. Sartre behält - unter erheblichem finanziellen Aufwand $^{156}$ - das letzte Wort und bietet Neuberg in „einer persönlichen Aussprache“ als Kompensation „tantiemenfrei sein jüngstes, aufsehenerregendes Stück ,Der Teufel und der liebe Gott““157 an, was dieser aus Prinzip ablehnt. Um weiteren Unannehmlichkeiten dieser Art vorzubeugen, geht Sartre, der das Stück auch andernorts (Spanien, Griechenland, Indochina) untersagen lässt, einen Schritt weiter und beschließt, es nur noch mit Einverständnis der Kommunistischen Partei des jeweiligen Landes zu autorisieren. Diese Verfügung wird vom Zürcher Europa-Verlag nicht allzu ernst genommen, wie sich zeigt, als zwei Jahre später das Volkstheater unter Direktor Leon Epp ohne Hindernisse die Aufführungsrechte erwirbt und sich des Dramas, nach dem gescheiterten Versuch von 1950, in einem zweiten Anlauf 1954 annimmt. Sartre erreicht die Nachricht kurzfristig in Salzburg, wo er sich gerade von dem strapaziösen Jahr 1954 erholt. Simone de Beauvoir erinnert sich an den Moment in La Force des choses:

In Salzburg, in einem Hotel der Altstadt, das seine ganze Anmut widerspiegelte, fing Sartre an zu arbeiten. Er hatte sich wieder gefunden. Wir besichtigten die Gegend mit ihren Bergen und Seen und fuhren eine Woche später nach Wien. Auf Grund eines Vertrages, den Nagel ohne Sartres Zustimmung unterzeichnet hatte, wurde eine Aufführung von Les Maines sales vorbereitet. Die Friedensbewegung hatte ihn darauf aufmerksam gemacht. Er protestierte und erläuterte seine Gründe auf der Pressekonferenz. Endlich sah ich im Museum die Brueghels, die Donau, den Ring, den Prater und die alten Kaffeehäuser, von denen man mir soviel

153 Jean-Paul Sartre. In: o. V.: Sartre besteht auf Zurückziehung seines Stückes. In: Österreichische Zeitung, 19.11.1952.

154 Erich Neuberg. In: o. V.: Sartre. Schmutzige Hände. In: Der Spiegel, 26.11.1952.

155 Weigel: Brief aus Wien, S. 180.

156 Neuberg verlangt 40.000 Schilling Schadenersatz, was 1952 etwa dem Dreifachen des durchschnittlichen ArbeitnehmerInnen-Jahreseinkommens entspricht. Cf. Löhne, Gehälter und Masseneinkommen in Österreich 1950-1957. In: Monatsberichte des Österreichischen Instituts für Wirtschaftsforschung 31, Oktober 1958, Beilage Nr. 54, S. 1-16, hier S. 4.

157 o. V.: Ausgleichsangebot Sartres an Theater am Parkring. In: Wiener Kurier, 05.01.1953. 
erzählt hatte. Die Abende verbrachten wir in mittelalterlichen Kellern des Stadtzentrums oder in vorstädtischen Wirtshäusern am Fuß der mit Weingärten bedeckten Hügel. ${ }^{158}$

(A Salzbourg, dans un hôtel de la vieille ville, qui en reflétait toutes les grâces, Sartre se remit à travailler; il se retrouvait. Lacs et montagnes, nous revisitâmes les environs et au bout d'une semaine, nous filâmes sur Vienne. Par suite de contrats signés, sans l'accord de Sartre, par Nagel, on se préparait à y jouer Les Mains sales; le Mouvement de la Paix l'en avisa; il protesta et s'expliqua au cours d'une conférence de presse. Enfin je vis les Breughel du musée, le Danube, le Ring, le Prater et les vieux cafés dont on m'avait tant parlé; nous nous attablions le soir dans des caves moyenâgeuses, au cœur de la ville, ou dans des cabarets des faubourgs, au pied des collines couvertes de vignobles blonds.) $)^{159}$

Dass Sartre von niemandem rechtzeitig informiert wird, muss erstaunen, so Friedrich Torberg, der damit womöglich unterschätzt, in welchem Ausmaß Sartre bürokratische Angelegenheiten scheut:

Warum der regsame Existentialdramatiker gerade seinen Theateragenten immer noch schalten und walten läßt, statt ihm das Schicksal des Hinaus-Geworfenseins zu bereiten, ist unerklärlich, und die legalistischen Formalitäten, auf die er bei seiner Wiener Pressekonferenz hinwies, sind keine Erklärung. Die wäre wohl eher darin zu suchen, daß es bis in die jüngste Vergangenheit zu zeitweiligen Reibungen zwischen Sartre und der Kommunistischen Partei kommen konnte, und tatsächlich wurden die Aufführungsrechte just in einem solchen Zeitpunkt an das Volkstheater vergeben. (Ob Sartre ihre Vergebung begünstigt hat, wird sich schwer feststellen lassen; behindert hat er sie nicht - das ging aus einem Pressebulletin des Europa-Verlags eindeutig hervor.) ${ }^{160}$

Der als prokommunistisch attackierte Volkstheater-Direktor Epp, in dessen Direktionszeit das Haus überdies Sartres Das Spiel ist aus (Regie: Gustav Manker, 1959), Die Eingeschlossenen (Regie: Leon Epp, 04.09.1960) und Die Troerinnen des Euripides (Regie: Gustav Manker, 1967) auf die Bühne bringt - da es für ihn „eine der wesentlichsten Aufgaben“ des Volkstheaters ist, „gegenwärtige Literatur zur Debatte zu stellen“161_, bemüht sich, „dem Autor zuliebe die antikommunisti-

158 Beauvoir: Der Lauf der Dinge, S. 301.

159 Beauvoir: La Force des choses, Bd. 2, S. 51f. Zusatzinformationen wie diese fehlen für Sartres Wien-Aufenthalt 1952, bei dem Beauvoir nicht anwesend ist. Was Sartre außerhalb des Friedenskongresses unternimmt, bleibt verborgen, mit Ausnahme des Hinweises, er habe eine ganze Nacht lang mit RussInnen Wodka getrunken (,[p]endant toute une nuit il avait bu de la vodka avec les Russes.“) Beauvoir: La Force des choses, Bd. 2, S. 20.

160 Torberg: Sartre oder Die ehrbare Koexistenz, S. 16.

161 Leon Epp: Kompromissloses Theater gegen Gefühlsträgheit und Wohlstandslethargie. Die elfte Direktion. Leon Epp seit 1952. In: Maske und Kothurn 13 (1967), Nr. 4, S. 299-317, hier S. 300. Epp führt 1952 ein Sonderabonnement ein für Premieren avantgardistischer Dramen, um das ,zum Teil etwas konservativ veranlagte Wiener Publikum nicht allzusehr zu schockieren“: „Es ist furchtbar schwer, in Wien mit zeitgenössischer Literatur durchzudringen. Der 
sche Tendenz des Stücks zu mildern“162. Nichtsdestoweniger bittet Sartre in einer - laut Torberg vom Weltfriedensrat orchestrierten - Pressekonferenz im Wiener Hotel Sacher am 23. September 1954 um Absage, während bereits die Generalprobe läuft: Er könne die Aufführung zwar nicht mehr verhindern, ,aber ich protestiere gegen sie, weil sie geeignet ist, die Spannungen zwischen Ost und West noch zu verschärfen. "163 Diese Einschätzung der politischen Macht seines Stücks wirkt in Anbetracht der Heftigkeit, mit der kommunistische Medien ihn noch kurz zuvor als „Feind aller fortschrittlichen Gedanken und Hasser der Menschheit, als Helfershelfer der amerikanischen Imperialisten“"164 behandelt haben, und der „Lobeshymnen“, zu denen Schmutzige Hände nun „rechtsstehenden Zeitungen“"165 Anlass gibt, nicht übertrieben. Die bürgerliche Presse hält das

Wiener hat einen Schutzpanzer um sich aufgerichtet. Was nicht 50 bis 60 Jahre alt ist, das läßt er nicht an sein Gemüt heran. Gegen diese Lethargie, diesen Schutzpanzer anzukämpfen, ist die Aufgabe meiner Spielplangestaltung, besonders im Sonderabonnement“ (S. 301).

162 Epp: Kompromissloses Theater gegen Gefühlsträgheit und Wohlstandslethargie, S. 300. Günter Anders, der sich anders als in den späten vierziger Jahren nun mit Sartre auf einer Wellenlänge befindet und ihn 1954 in Wien trifft, steht mit ihm in sporadischem Briefkontakt und schreibt ihm über den Volkstheater-Direktor: „Armer Eppl. [!] Vor einem halben Jahr wurde er als prokommunistisch angegriffen, weil er im Volkstheater die deutsche Version von ,Silver Tassie“ von O’Casey präsentiert hatte, die meine Frau und ich verfasst hatten.“ [Übers. d. Verf.] („Pauvre Eppl. Il y a une demi[-]année [qu']il fut attaqué comme pro-communiste parce qu'il avait pr[é]senté au Volkstheater la version allemande de ,Silver Tassie“ par O’Casey, que ma femme et moi av[ons] préparée.“ [!]) Briefwechsel Günther Anders - Jean-Paul Sartre. 25.09.1945-17.07.1970. Literaturarchiv der Österreichischen Nationalbibliothek, Wien (LIT), Sign.: 237/B1508. Anders' letzter Brief vom 17.07.1970, gerichtet an Sartre und Vladimir Dedijer, thematisiert das Russell-Tribunal. Auf ihre Initiative (gemeinsam mit Noam Chomsky) zurückgehend und auf Einladung des österreichischen Kanzlers Bruno Kreisky findet vom 11. bis 15. September 1972 in Linz das „Bertrand Russell Centenary Symposium“ statt, an dem der gesundheitlich angeschlagene Sartre jedoch nicht teilnimmt: „It concerned the development of economic imperialism since the beginning of the nineteenth century, and the politics of spheres of influence during the same time." o. V.: Introductory Note. In: Spheres of influence in the Age of imperialism. (Papers submitted to the Bertrand Russell Centenary Symposium, Linz, Austria, September 11th to 15th, 1972.) Nottingham 1972, S. 1.

163 Jean-Paul Sartre: Sartre: „Ich protestiere, kann aber die Aufführung nicht verhindern“. In: Weltpresse, 23.09.1954.

164 o. V.: Ein Theaterskandal. In: Österreichische Zeitung, 30.11.1951. Zur tatsächlichen Wirksamkeit ist auch Milo Dors Stellungnahme aufschlussreich: Les Mains sales habe ihn so sehr beeindruckt, dass es sein „Verhalten der Sowjetunion [...] gegenüber auf lange Zeit, letztlich bis heute, beeinflußt. Ich bewundere die klare Eloquenz, mit der die Franzosen ihre Gedanken zum Ausdruck bringen.“ Dor: Auf dem falschen Dampfer, S. 204.

165 hs.: Viel Wasser um „Schmutzige Hände“. In: Neue Wiener Tageszeitung, 24.09.1954. 
Stück für „weder pro- noch antikommunistisch“, es sei erst durch die KommunistInnen „wirklich zu einem antikommunistischen Stück geworden.“166

Sartre wiederholt vor den Wiener JournalistInnen, es sei nicht „gegen den Kommunismus geschrieben, sondern sollte den Konflikt zwischen den einzelnen Widerstandsgruppen darlegen“; auch wenn er selbst keine antikommunistischen Tendenzen darin erkenne, möchte er es in Wien, „einem der zwei bis drei neuralgischen Punkte der gegenwärtigen Welt“"167, nicht gespielt wissen. Vor den in Österreich anstehenden Wahlen sei „nicht die nötige ruhige Atmosphäre zur Aufnahme seines Stückes gegeben“, so Sartre, für Die Presse eine „für den Programmatiker und Vorkämpfer des politischen Engagements der Literatur immerhin eigenartige Feststellung“"168. Der Protest des Autors im Hotel Sacher löst eine wahre „Artikelflut“ aus, wobei er mit Ausnahme der kommunistischen Blätter „kritisiert, ja sogar beschimpft“"169 wird, wie Porpaczy zusammenfasst. Dies betrifft allerdings die Person Sartre und ihre politischen Entscheidungen, für das Theaterstück gilt genau das Gegenteil: Nach vier Jahren des Scheiterns ist die erste Aufführung der Stadt unter dem Titel Schmutzige Hände am 24. September 1954 im Volkstheater zu sehen und erntet, als „eine der besten, die wir in Wien gesehen haben“170, von Presse und Publikum „stürmischen Beifall““171.

166 Piero Rismondo: Der Mord als Selbstbestätigung. In: Die Presse, 02.10.1954.

167 o. V.: Makabres Intermezzo. In: Die Presse, 24.09.1954.

168 o. V.: Makabres Intermezzo. In: Die Presse, 24.09.1954.

169 Porpaczy: Frankreich - Österreich, S. 227. Günther Anders schreibt Sartre am 25. September 1954, einen Tag nach der Premiere: „Ich nehme an, Sie haben alle Kommentare zu Ihrem Interview hier gesehen. Kopien aus den meisten Zeitungen befinden sich in meinen Händen; niemand hat jedoch das, was ich für den springenden Punkt halte, geschrieben: dass diese Kritik zum Zeitpunkt, als Sie das Stück geschrieben haben, nichts bedeutete und nicht als Geschenk an die Feinde derer genützt werden kann, die Sie kritisiert haben: Hitler und Pétain“. [Übers. d. Verf.] (,Je présume que vous ayez vu tous les commentaires sur votre interview ici. Des copies de la plupart des journaux se trouve[nt] dans mes mains; personne, cependant n'a [é]crit ce qui me semble le punctum saliens: qu'à l'[é]poque o[ù] vous avez [é]crit la pièce cette critique ne signifia point et ne pouvez pas être exploitée comme un cadeau fait aux en[n]emies de ceux, que vous avez critiques: à Hitler et à P[é]tain [!]“.) Briefwechsel Günther Anders Jean-Paul Sartre. 25.09.1945-17.07.1970. Literaturarchiv der Österreichischen Nationalbibliothek, Wien (LIT), Sign.: 237/B1508.

170 Rismondo: Der Mord als Selbstbestätigung. In: Die Presse, 02.10.1954.

171 Karl Maria Grimme: Sartre kontra Sartre. In: Neue Wiener Tageszeitung, 26.09.1954. Das Stück sei der Fall eines „großen und einhelligen Publikums- und Presseerfolges“, heißt es im Wiener Kurier (o. V.: „Rose Bernd“ am Volkstheater, 01.10.1954), wobei gerade Sartres (versuchter) Theaterbann als „Reklame“ (Hans Weigel: Sartre macht Reklame. In: Bild-Telegraf, 23.09.1954) gewirkt habe. 
Auf die Existentialismus-Rezeption wirken sich die Theater-Skandale und der realpolitisch folgenlos bleibende Völkerkongress merklich aus. „Nach Sartres offener Hinwendung zum Kommunismus begann die Haltung zu seiner Person sich auf beiden Seiten zögernd in ihr Gegenteil zu verkehren“172, bemerkt Kraus zu Recht, nur dass sich die ,Verkehrung recht zügig einstellt. Die Arbeiter-Zeitung findet es nach der Pressekonferenz im Sacher „betrüblich, einen Mann vom Format Sartres [...] auf Befehl über den nun unangenehm gewordenen eigenen Schatten springen zu sehen“"173. Bei der Presse, die vom Stück ebenfalls begeistert ist, hat man gar „den bedrückenden Eindruck, einen Mann sprechen zu hören, der seinen überfeinerten Intellekt schließlich selbst an die Kette gelegt, einen Revolutionär, der sich freiwillig in die tiefste Sklaverei des menschlichen Geistes begeben hat. “174 Während die westlich ausgerichteten Medien zwar die Schmutzige Hände- Aufführung gutheißen, aber den homo politicus Sartre mit Ablehnung strafen, ist der Ton der KP-nahen Blätter, die das Theaterstück bekämpfen, den Autor betreffend wie ausgewechselt. Wurden noch ,seine konkretesten Solidaritätskundgebungen bis Anfang August [1952] von der kommunistischen Presse entweder ignoriert oder beschimpft“"175, sorgt der Völkerkongress für ein abruptes Ende der Kritik. Das Österreichische Tagebuch, in dem jahrelang zu lesen war, der Existentialismus sei an „flacher Verworrenheit und leichtfertiger Antihumanität kaum übertreffbar“176, freut sich, dass der „Routinier der Verzweiflung“ nach „philosophischen Kunststücken und literarischen Kapriolen““177 nun den richtigen Weg eingeschlagen und „die Zwangsjacke eines unnatürlichen Snobismus und einer unfruchtbaren Philosophie“"178 abgelegt hat. Auch die Österreichische Zeitung ist erleichtert, den „Pseudopropheten der Finsternis und der Verzweiflung“"179 die „Dürftigkeit seiner Gedanken“"180 hinter sich lassen zu sehen, speziell sein Nichtanerkennen der Kräfte des Fortschritts, seinen Glauben an die Unabhängigkeit des

172 Kraus: Kultura, S. 155.

173 o. V.: Herr Sartre protestiert. In: Arbeiter-Zeitung, 24.09.1954.

174 o. V.: Makabres Intermezzo. In: Die Presse, 24.09.1954.

175 Jacob: Die Auseinandersetzung Sartre-Camus. In: Geistiges Frankreich, 13.10.1952.

176 Walter Hollitscher: Ist der Existentialismus humanistisch? In: Österreichisches Tagebuch 3 (1948), Nr. 12, S. 11-12, hier S. 11.

177 o. V.: Sartre. In: Tagebuch, 08.11.1952.

178 Benedek: Zweimal Jean Paul Sartre. In: Tagebuch, 03.01.1953.

179 E. K.: Eine Verzerrung des Menschen. In: Österreichische Zeitung, 15.11.1947.

180 O. S.: Die Dramatik Sartres - eine Predigt des Menschenhasses. In: Österreichische Zeitung, 16.12.1950. 
Einzelnen von der menschlichen Gemeinschaft und von sozialen Umständen, sowie sein Ignorieren übergeordneter Begriffe von Gut und Böse. ${ }^{181}$

Der theoretische Hintergrund von Sartres Wandel bleibt in der Berichterstattung weitgehend unkommentiert. Ab dem Moment, da er den Marxismus als Philosophie der Zeit („philosophie de notre temps“(182) anerkennt, sucht er dessen sklerotische“ Theorie mit seiner Freiheitsphilosophie, die sich am Rande des Marxismus („en marge du marxisme“183) und nicht gegen ihn entwickelt habe, zu konsolidieren. Zuvor erscheint er ihm unvereinbar mit dem eigenen Denken, das ausgehend von Descartes die Selbstvergewisserung des Subjekts im cogito („la vérité absolue de la conscience s’atteignant elle-même“184) als Ausgangspunkt für jede weitere Wahrheit setzt. Dieses für Sartre wesentliche Fundament („ma pensée philosophique essentielle“185) hätte er aufgeben und sein erstes philosophisches Hauptwerk L'Être et le Néant verleugnen müssen: Ausgehend von der Materialität der Welt - Marx' Priorisierung des Objekts vor dem Subjekt (,priorité de l’objet sur le sujet“(186) -, kann das Bewusstsein nicht jene Freiheit sein, die bei Sartre (als pour-soi) der dinglichen Welt (des en-soi) Bedeutung verleiht.

Sartres Freiheitsauffassung verändert sich nun insofern, als er sich von der L'Être et le Néant zugrunde gelegten „Freiheit eines klassenlosen Menschen““187

181 Cf. Hollitscher: Ist der Existentialismus humanistisch?, S. 12. Die „stur-individualistische Grundhaltung“ des Existentialismus und die „Diktion der inneren Willensfreiheit“ veranlassen zuvor den österreichischen Kulturphilosophen Theodor Hartwig zu einer Studie mit dem unmissverständlichen Titel Der Existentialismus. Eine politisch reaktionäre Ideologie. Wien 1948, S. 15: „Es ist utopisch zu glauben, man könne Menschen durch Vernunft allein zur Vernunft bringen, während rückständige soziale Verhältnisse sich notwendig hemmend auf die Entschlußkraft eben dieser Menschen auswirken müssen.“

182 Jean-Paul Sartre: Questions de méthode. In: Sartre: Critique de la raison dialectique (précédé de Questions de méthode), Bd. 1: Théorie des ensembles pratiques. Paris 1974, S. 29.

183 Sartre: Questions de méthode, S. 22.

184 Sartre: L'Existentialisme est un humanisme, S. 57.

185 Sartre: Sartre, S. 85.

186 Sartre: L'Être et le Néant, S. 626.

187 Sartre: Volksfront nicht besser als Gaullisten. In: Der Spiegel, 12.02.1973. Den von kommunistischer Seite vehement vorgebrachten Vorwurf, er mauere das Individuum in seiner Subjektivität ein, hält Sartre für unzutreffend. Die Subjektivität fasse er nicht als strikt individuell auf, denn im cogito „erreichen wir [...] uns selbst im Angesicht des anderen, und der andere ist für uns ebenso gewiß wie wir selbst“ („nous nous atteignons nous-mêmes en face de l'autre, et l'autre est aussi certain pour nous que nous-mêmes“). Sartre: L'Existentialisme est un humanisme, S. 165. (Sartre: L'Existentialisme est un humanisme, S. 58.) Allerdings nimmt die Intersubjektivität weniger die Gestalt eines harmonischen Miteinanders als die eines immerwährenden Konflikts an, der bei Sartre „der ursprüngliche Sinn des Für-Andere-seins“ (,le sens originel de l'être-pour-autrui“) ist. Sartre: Das Sein und das Nichts, S. 638. (Sartre: L'Être et le Néant, S. 404.) 
abwendet und die Situation als das konkrete Maß der Möglichkeiten des pour-soi neu gewichtet: „Ich habe versucht, Allgemeinheiten über die Existenz des Menschen zu sagen, ohne dabei zu berücksichtigen, daß diese Existenz immer historisch situiert ist und sich von dieser Situation her definiert.“ („J'ai essayé de donner des généralités sur l'existence de l'homme, sans tenir compte du fait que cette existence est toujours située historiquement et qu'elle se définit à partir de cette situation.“188) Zwar beschreibt er den Menschen schon Mitte der vierziger Jahre als eine Freiheit in Situation (,une liberté en situation“) unter Berücksichtigung biologischer, psychischer und sozialer Phänomene (,phénomènes biologiques, psychiques et sociaux“189), doch erhält all das, was als Faktizität - das die Freiheit Beschränkende (,sa propre restriction“190) - vorhanden war, nun eine entscheidendere Rolle, wie Sartre in der New Left Review äußert:

The individual interiorizes his social determinations: he interiorizes the relations of production, the family of his childhood, the historical past, the contemporary institutions, and he then re-exteriorizes these in acts and options which necessarily refer us back to them. ${ }^{191}$

Im Film-Interview Sartre präzisiert Sartre das Verhältnis von Freiheit und Konditionierung mit der schon Questions de méthode (1960) zugrundeliegenden Formel, man erschaffe sich auf der Grundlage dessen, was aus einem gemacht worden sei („on se fait à partir de ce qu'on a fait de vous“), betont aber, dem Freiheitsgedanken immer treu zu bleiben (,toujours fidèle à la notion de liberté“192). Was er bereits 1946 in „Matérialisme et révolution“ beanstandet, das zu starke Haften am Determinismus („l'adhésion trop étroite au déterminisme universel") seitens der Neomarxisten in ihrem Glauben an eine wahre menschliche Natur („une vraie nature humaine“193), behält Gültigkeit, weshalb er sich nicht als marxistisch, sondern als „marxien“ bezeichnet: „Wenn der Marxismus dialektisch ist, bin ich völlig einverstanden. Aber es gibt einen marxistischen De-

188 Sartre: Sartre. Ein Film, S. 63. Sartre: Sartre, S. 97.

189 Jean-Paul Sartre: Réflexions sur la question juive (1946). Présentation par Arlette ElkaïmSartre. Paris 1954, S. 96, 64.

190 Sartre: L'Être et le Néant, S. 540. Cf.: „Es ist mein Platz, mein Körper, meine Vergangenheit, meine Position, insofern sie durch die Indikationen der anderen bereits bestimmt ist, schließlich meine grundlegende Beziehung zu Anderen.“ („C'est ma place, mon corps, mon passé, ma position en tant qu'elle est déjà déterminée par les indications des autres, enfin ma relation fondamentale à autrui.") Sartre: Das Sein und das Nichts, S. 846 (Hervorhebung im Oritinal). (Sartre: L’Être et le Néant, S. 534 [Hervorhebung im Oritinal].)

191 Sartre: Itinerary of a Thought, S. 45.

192 Sartre: Sartre, S. 76, 75. Cf. Sartre: Questions de méthode, S. 63.

193 Jean-Paul Sartre: Matérialisme et révolution. In: Sartre: Situations, III, S. 153, 158 (Hervorhebung im Oritinal). 
terminismus über die Wertung der individuellen oder kollektiven Aktion, den ich nicht akzeptiere, weil ich der Idee der Freiheit treu geblieben bin.“194 Aus kommunistischer Perspektive ist dies durchaus als eigenwilliger Marxismus akzeptabel, wie der folgende undatierte Brief aus dem Nachlass Ernst Fischers nahelegt:

Lieber, verehrter Jean Paul Sartre,

Sie sind, was die Welt heute braucht: Resistance. Wo Dummheit sich breit macht, wo Unrecht geschieht, sind Sie der Widerspruch, der Widerstand. In Ihrem Wesen und Werk vereinigt sich der Geist der Kritik mit der Unbeirrbarkeit des Partei Ergreifenden. In geistiger Unabhängigkeit haben Sie für den Sozialismus Partei ergriffen, als eigenwilliger Marxist an seinen Kämpfen teilnehmend, zur Entwicklung seiner Ideen beitragend, dem Stillstand der Dogmen die unablässige Bewegung des Denkens entgegensetzend. Voll Bewunderung für die Fülle Ihrer literarischen, philosophischen, publizistischen Leistungen, für Ihre Tapferkeit, Lauterkeit und schöpferische Unruhe, grüße ich Sie als einen der Wegbereiter einer integralen Menschheit und Weltkultur, als einen der unentbehrlichen Menschen unseres Zeitalters.

Ernst Fischer ${ }^{195}$

Nach Günther Nennings Dafürhalten geht Sartre mit dem Marxismus einfach um „wie ein vernünftiger Mensch westlich von den deutsch-österreichischen Marxfressern“:

Existentialismus ist ein Materialismus: er sieht die materiellen Umstände, wie sie westöstliche Ordnung uns einträchtig bescheren. Existentialismus ist ein Idealismus: er hält für möglich, daß der Mensch trotzdem tut, was er sich an Ideen vorgenommen hat im eigenen Kopf. Freilich unter absurden Schwierigkeiten, mit absurd totalem Heldentum, und ohne wirkliche Änderung der ringsum absurden Zustände. ${ }^{196}$

Fischls Meinung nach, die an das zwischen Sartre und den P. C.-Mitgliedern vorhandene Misstrauen auch während der Weggenossenschaft denken lässt, werde Sartre „trotz seines Liebeswerbens von den Kommunisten zwar für ihre Ziele gebraucht, aber innerlich doch abgelehnt“, denn er sei in Wirklichkeit weder Kommunist (wegen seines absoluten Freiheitsbegriffs) noch Materialist (da alle Probleme für ihn aus dem Bewusstsein entstünden), sondern schlicht: „Individualist und asozial“197. Ein solches Festhalten an Sartres früheren Positionen vor der Wegbegleiter-Phase steht unter anderem in Zusammenhang mit der späten Veröffentlichung von Das Sein und das Nichts 1952, im Jahr des Völ-

194 Sartre: Volksfront nicht besser als Gaullisten. In: Der Spiegel, 12.02.1973.

195 Ernst Fischer: TNL [Teilnachlass]. Typoskript. Literaturarchiv der Österreichischen Nationalbibliothek, Wien (LIT), Sign.: 37/B299.

196 Nenning: Sankt Sartre, S. $26 \mathrm{f}$.

197 Fischl: Idealismus, Realismus und Existentialismus der Gegenwart, S. 312. 
kerkongresses. Die Verzögerung dieser und anderer Übersetzungen (die meisten Vorkriegswerke erscheinen 1949/50) führt zu einer in Bezug auf die Entstehenschronologie undifferenzierten Aufnahme von Ideen aus der frühen phänomenologischen (der dreißiger) und der originär existentialistischen Phase (der vierziger Jahre) kurz vor oder gleichzeitig mit Sartres Annäherung an den Kommunismus. So finden sich Anspielungen auf die Die schmutzigen Hände-Aufführungen in Kombination mit Sartres Ruf eines Nihilisten bei dem von den amerikanischen Besatzungstruppen lizenzierten Erfolgsradiosender Rot-Weiß-Rot, speziell in dem von 1953 bis 1955 monatlich ausgestrahlten Kabarett-Programm von Helmut Qualtinger und Carl Merz, das sich, von „hoher Qualität“ und „großer Zugkraft“198, um tagesaktuelle politische Nuancen bemühe. Im Kabarett-Stück „Der Gehirnaustausch“ heißt es:

2. SPRECHER [...] Stellen Sie sich vor, ein Wiener Operetten-Librettist sieht die Welt mit den Augen Jean Paul Sartres ... [...]

ADELE Du blickst hinaus. Was siehst du?

EISENSTEIN Den drohenden Kahlenberg, das Gerippe des Riesenrades und die giftgrünen Sümpfe des Praters ... Brrrrrrrrr! Schüttelt sich

ADELE Und wir sind dazu verdammt, unser ganzes Leben hier zu verbringen.

EISENSTEIN Ah, wer sagt dir, daß wir noch leben?

198 Viktor Ergert: 50 Jahre Rundfunk in Österreich, Bd. 2: 1945-1955. Salzburg 1975, S. 190, 129. Der Rundfunk vervielfacht vor allem die Wirkung des existentialistischen Theaters (cf. dazu Unterwegers Aufsatz „L'Être ou le Néant?“). Auch „die geistige Wechselwirkung“ zwischen Buch und Rundfunk ist gerade „in den Zeiten, da [diese] Grenzen geographisch und geistig hermetisch geschlossen waren“ (Hans Nüchtern: Buch und Rundfunk. In: Österreichisches Tagebuch, 05.12.1947), elementar, betont Hans Nüchtern, Direktor der literarischen Abteilung der RAVAG, die zu dieser Zeit mit der „Radiodiffusion française“ jede Woche 45 Minuten Sendung austauscht. Für die französischen Alliierten stellt das Radio (die Sendergruppe West, bestehend aus Radio Vorarlberg in Dornbirn-Lauterach und der Zweigstation Radio Innsbruck) von Anfang an ein wertvolles Instrument zur Verbreitung französischer Kultur in Österreich dar (,un instrument précieux de diffusion de la culture et des idées françaises en Autriche“), das sie jedoch in der Praxis vergleichsweise wenig benützt. Haut Commissariat: Deux Ans et demi de présence française en Autriche, S. 45. Informationen zu Frankreich erreichen die HörerInnen auch vermittelt durch die Bulletins Kulturelles und Geistiges Frankreich über externe Stationen: „Fast regelmäßig werden unsere Aufsätze von den Sendern RAVAG und Rot-Weiß-Rot ausgewertet.“ Redaktion: Ein Jahr „Kulturelles“. In: Kulturelles, 22.03.1948. 199 Carl Merz und Helmut Qualtinger: Gehirnaustausch. In: Merz und Qualtinger: „Brettl vor dem Kopf“ und andere Texte fürs Kabarett. (Helmut Qualtinger, Werkausgabe 2.) Wien 1996, S. 74-89, hier S. 82-86. 
ADELE Herr Sartre. Er bekommt ganz anständige Tantiemen für uns. [...]

SPRECHER Das logische Gegenstück von Jean Paul Sartres „Fledermäusen“ wäre Johann Strauß mit seiner Operette „Das ehrbare Dirndl“ oder „Die schmutzigen Patscherln“. ${ }^{199}$

In einem weiteren Stück, „Und Ithaka wartet ... Aus dem Tagebuch des letzten Troja-Heimkehrers“, sind Anspielungen auf Les Mains sales eingebettet in ein dichtes Verweisnetz (Sartres Euripides-Adaption Les Troyennes, engagierte Literatur, der Kalte Krieg, Kellertheater). Odysseus' GefährtInnen rufen hier mehrfach „Kunst ist unpolitisch“ aus, als Odysseus „der rettende Einfall“ kommt:

Ich stopfte ihnen die ,Schmutzigen Hände‘ in die Ohren, nicht meine und nicht ihre, sondern die des Herrn Sartre. Das wirkte. Er protestierte zwar dagegen, aber das wirkte erst recht. Da hörte ich mich plötzlich selber rufen: Koexistenz! Koexistenz! Und sah, wie weit es mit mir durch den trojanischen Krieg gekommen war. ${ }^{200}$

Auf die Frage der Psychologin Kirke: „Fanden Sie es unnatürlich, daß Ihr Onkel Ödipus sich mit seiner Mutter vermählte?“, folgt sodann die Antwort: „Wenn es nicht von einem französischen Dramatiker stammt und in einem Kellertheater aufgeführt wird, nicht.“201 Im Gegensatz zu diesen Beispielen ist im Stück „Ob wir das noch erleben?“, in dem der Sprecher am 14. September 1954 den HörerInnen als Abendunterhaltung im „Volkstheater: ,Die schmutzigen Füße', ein Drama aus den steirischen Bergen“202, ankündigt, ein entsprechendes Wissen vorausgesetzt, nämlich die Geläufigkeit des Stücks Die schmutzigen Hände, da hier der Name Sartre nicht fällt. Ideal-RezipientInnen wäre zudem imstande, die Konnotation von „steirische Berge“ zu entschlüsseln (Graz als Ort der Uraufführung des Stücks). Die Praxis der Sartre-Satiren, die zumindest eine oberflächliche Kenntnis erfordert, um zu funktionieren, gibt letztlich auch Aufschluss über das Ausmaß der Bekanntheit Sartres. Diese erreicht ihren Zenith durch die sich 1954 vollziehenden Ereignisse samt mächtigem Widerhall in den österreichischen Medien, nachdem die Volkstheater- und Parkring-Absagen sowie Sartres Teilnahme am Völkerkongress mit begleitendem Presse-Boykott zu Beginn der fünfziger Jahre schon für eine diesbezügliche Sensibilisierung gesorgt haben.

Dass die meisten positiven Reaktionen der auflagenstarken bürgerlichen Presse der bewussten (Um-)Interpretation von Les Mains sales als antikommunistisches Stück geschuldet sind, zeigt neuerlich, nachdem schon katholische

200 Carl Merz und Helmut Qualtinger: Und Ithaka wartet ... Aus dem Tagebuch des letzten Troja-Heimkehrers. In: Merz und Qualtinger: „Brettl vor dem Kopf“ und andere Texte fürs Kabarett, S. 60-73, hier S. 63, 64.

201 Merz und Qualtinger: Und Ithaka wartet ..., S. 65.

202 Carl Merz und Helmut Qualtinger: Ob wir das noch erleben? In: Merz und Qualtinger: „Brettl vor dem Kopf“ und andere Texte fürs Kabarett, S. 29-45, hier S. 41. 
und kommunistische Periodika existentialistische Inhalte $\mathrm{zu}$ ihrem Nutzen dehnen, wie Kulturimporte „oft instrumentalisiert“ und „nur deswegen eingeführt“ werden, „weil sie schon etablierte Positionen des Aufnahmekontextes unterstützen. “203 Wandelbarkeit von Kulturgütern stellt entsprechend einen Erfolgsfaktor für ihren Transfer dar. Bourdieu kommentiert, dass sich vor allem ausländische AutorInnen als variabel erweisen:

Bei den fremden Autoren zählt sehr oft nicht das, was sie sagen, sondern das, was man sie sagen lassen kann. Daher zirkulieren gewisse gut dehnbare Autoren sehr gut. Die großen Prophezeiungen sind vieldeutig. Das ist einer ihrer Vorzüge, und deshalb findet man sie an allen Orten, zu allen Zeitpunkten, in allen Zeitaltern, bei allen Generationen usw. Die Denker mit großer Dehnbarkeit sind ein gefundenes Fressen, wenn ich so sagen darf, für eine vereinnahmende Interpretation und für eine strategische Verwendung. ${ }^{204}$

(Très souvent, avec les auteurs étrangers, ce n'est pas ce qu'ils disent qui compte, mais ce qu'on peut leur faire dire. C'est pourquoi certains auteurs particulièrement élastiques circulent très bien. Les grandes prophéties sont polysémiques. C'est une de leurs vertus et c'est pour cela qu'elles traversent les lieux, les moments, les âges, les générations, etc. Donc, les penseurs à grande élasticité sont pain bénit, si je peux dire, pour une interprétation annexionniste et pour les usages stratégiques.) ${ }^{205}$

Sartre zählt, wie sich am österreichischen Kontext ablesen lässt, zu dieser hochelastischen Gruppe, wobei die Kulturtransfer-TheoretikerInnen anders als Bourdieu die Aufnahme selbst im Falle von , annexionistischen' Motiven nicht als negative Verfremdung empfinden, vielmehr kommt es ihnen gerade auf diesen „semantischen Zusatz“206 an. Sartres Denken erlaubt umso mehr Anverwandlungen, als die Bandbreite seines Schreibens so immens ist; Collins nennt den Autor gar ,a ,nothingness“ of vital energy“, „a blank, ready to fill itself with whatever is available and to transform it into the attention center of the future.“207 Die Beliebigkeit, die hier anklingt, ist Gegenstand zahlreicher humoristischer Ausführungen, etwa in Vians Roman L'Écume des jours, in dem sich die Figur Chick wundert, wie man sich nicht für einen Menschen wie Partre interessieren könne, der imstande sei, alles Mögliche über alles Mögliche zu schreiben, und mit welcher Präzision. („Comment ne pas s’intéresser à un homme comme Partre, capable d'écrire

203 Espagne: Die Rolle der Mittler im Kulturtransfer, S. 313.

204 Pierre Bourdieu: Die gesellschaftlichen Bedingungen der Zirkulation der Ideen. In: Bourdieu: Forschen und Handeln. Vorträge am Frankreich-Zentrum der Albert-Ludwigs-Universität Freiburg (1989-2000). Hg., übersetzt und kommentiert von Joseph Jurt. Freiburg im Breisgau 2004, S. 35-48, hier S. 41.

205 Bourdieu: Les Conditions sociales de la circulation internationale des idées, S. 5.

206 Espagne: Die Rolle der Mittler im Kulturtransfer, S. $311 \mathrm{f}$.

207 Collins: The Sociology of Philosophies, S. 776. 
n'importe quoi sur n'importe quel sujet et avec quelle précision.“208) Dass er diese Textmengen überdies in kürzester Zeit verfasst, mindestens fünf Artikel pro Woche, treibt den Partre-Sammler („,collectionneur de Partre“209) alsbald in den finanziellen Ruin. Die Satire auf die „Schreibmaschine“210 Sartre liegt näher an der Wahrheit - bisweilen entstehen 80 Seiten pro Tag - als vermutet. Die Quantität tut der Qualität keinen Abbruch, beruhigt die Redaktion des französischen Dokumentationszentrums in Wien, die den Existenzialismus Sartre’scher Prägung als „eine gewaltige Leistung des Geistes“ bezeichnet, „die mit der gleichen Virtuosität eine philosophische Dissertation oder ein Drehbruch hervorbringt“, darunter einige „Meisterwerke“211. Auch Die Presse wird schließlich vom „immensen Fleiß[]“ Sartres und der „faszinierend breiten Palette seines Könnens“‘212 schwärmen.

Doch auch das, was nicht als chef d'œuvre oder Meisterleistung gelten kann, scheint auf eine gewisse Weise nachahmenswert. Trotz der vielen Seiten „trüben Unsinns“, die Sartre laut dem österreichischen Schriftsteller und Kritiker Herbert Eisenreich bisweilen verfasst, sei seinen Entwicklungen vor allem Positives abzugewinnen: „Und selbst wenn Sartre hier und dort irrt: er irrt nicht aus Schlamperei und Ignoranz und Selbstgefälligkeit. Überhaupt sollten wir den Wert des Irrtums nicht unterschätzen!“213 Scheuch stimmt zu: „Darin liegt die Stärke und die Schwäche Sartres: daß er ein Suchender geblieben ist, ein kritischer und destruktiver Geist, der manchmal falsche Wege einschlägt aber welchem Wanderer passiert das nicht?،“214 Trägt der Wandernde besonders viel Verantwortung - und ist, „[o]bwohl er es nicht weiß“, wie 1974 Marcuse äußert, „das Gewissen der Welt“215_, dürfe dies nicht passieren, meint hingegen Manès Sperber. Er urteilt weniger mild über die Irrtümer, die sich Sartre mit

208 Vian: L'Écume des jours, S. 257.

209 Vian: L’Écume des jours, S. 70.

210 Nenning: Sankt Sartre, S. 21. Cf. Collins: The Sociology of Philosophies, S. 776: „Fanatically writing, he produces as many as 80 pages a day [...]. Sartre is the energy vortex of his network, reading and writing about everything that comes into its purview.“

211 o. V.: Polemik um Jean-Paul Sartre. In: Kulturelles, 02.02.1948.

212 ile: Ein Leitfossil. In: Die Presse, 17.04.1980.

213 Eisenreich: Sartres Situationen. In: Die Zeit, 05.04.1956.

214 Scheuch: Literatur der äußersten Situation, S. 10. Manche blenden die „politischen Zickzack-Kurse“ so weit aus, dass nur „Achtung und Hochschätzung für Sartre“ übrig bleiben, so der österreichische Psychotherapeut Josef Rattner, der nach 1938 in die Schweiz (später nach Deutschland) geht, wo er dem „kühnen und progressiven Denker“ dann sein „langes Leben hinweg die Treue gehalten“ hat. Josef Rattner: Jean-Paul Sartre. Ein Essay. Berlin 2016, S. 5.

215 Traugott König: Sartre, Jean-Paul, S. 334. John Gerassi wird Sartre dann später zum verhassten Gewissen seines Jahrhunderts im Titel seiner Studie Jean-Paul Sartre. Hated Conscience of his Century machen (Vol. 1, Protestant or Protester? Chicago 1989). 
„einer bestürzenden nachtwandlerischen Sicherheit“ zu eigen gemacht habe: Als „einer der weitaus bedeutendsten Geister dieses Jahrhunderts“ und „dank seiner überragenden Gabe, alles, auch das Komplizierteste meisterlich zu erklären und das Abwegigste überzeugend darzulegen“, sei Sartre fähig, Andersdenkende ,ins Unrecht zu setzen“, weshalb Sperber es ihm „heftiger als allen anderen aufs entschiedenste übelgenommen“ hat, „der wirksamste intellektuelle Propagandist der stalinschen und poststalinschen Politik““216 geworden zu sein.

Sartres Heranrücken an den Kommunismus und damit auch seine beiden Wien-Aufenthalte seien Versuche gewesen, zwanzig Jahre zurückliegende Fehlurteile zu kompensieren, deutet Simone de Beauvoir im Rückblick an. Nach dem Zweiten Weltkrieg, der Sartres Leben zweiteilt und politisiert, kommt er für ein in seinen Augen historisches Ereignis („un événement historique“217), den Völkerkongress, nach Wien, nachdem er 1934 zwei Reisen dorthin aufgrund historischer Ereignisse verworfen hat. Zunächst lassen die Februarkämpfe 1934 Beauvoir und Sartre eine von Berlin aus geplante Reise abbrechen, wie Beauvoirs Memoiren La Force de l'âge aufklären:

Während meines Berlin-Aufenthaltes [wo Sartre seinerzeit Husserl studiert] versuchten die österreichischen Sozialisten die Unzufriedenheit der Arbeiter auszunutzen, um der Ausbreitung des Nazismus entgegenzuwirken; sie organisierten einen Aufstand, den Dollfuß im Blut erstickte. Dieser Fehlschlag deprimierte uns. Wir wollten dem Rad der Geschichte nicht in die Speichen greifen, wollten uns aber einbilden, es drehe sich in unserem Sinne. ${ }^{218}$

(Pendant mon séjour, les socialistes autrichiens tentèrent d'exploiter le mécontentement ouvrier pour s'opposer à la montée du nazisme; ils déclenchèrent une insurrection que Dollfuss écrasa dans le sang. Cet échec nous assombrit un peu. Nous refusions de toucher à la roue de l'Histoire, mais nous voulions croire qu'elle tournait dans le bon sens. $)^{219}$

Ein noch deutlicherer Hinweis auf ihre apolitische Vorkriegsposition folgt in Beauvoirs Kommentar zum zweiten, von Prag aus geplanten, aber wiederum wegen politischer Zwischenfälle ausbleibenden Wien-Besuch, nachdem der austrofaschistische Kanzler Dollfuss beim nationalsozialistischen Juli-Putsch 1934 im Bundeskanzleramt in Wien erschossen worden war:

Wir hatten vor, nach Wien zu fahren. Als wir aber eines Morgens das Hotel verließen, sahen wir Menschenansammlungen auf der Straße. Die Leute rissen sich um Zeitungen mit Riesenüberschriften, in denen uns der Name Dollfuß auffiel und ein Wort, das mit M

216 Sperber: Nur eine Brücke zwischen Gestern und Morgen, S. 41, 43.

217 Sartre: Ce que j'ai vu à Vienne, c’est la Paix. In: Les Lettres françaises, 01.-08.01.1953.

218 Beauvoir: In den besten Jahren, S. $155 \mathrm{f}$.

219 Beauvoir: La Force de l'âge, S. $207 \mathrm{f}$. 
begann und dessen Sinn wir errieten. Ein deutschsprechender Passant gab Sartre Auskunft: Dollfuß war ermordet worden. Heute scheint mir, daß dies ein Grund mehr gewesen wäre, sofort nach Wien zu fahren. Aber wir waren so sehr vom Optimismus der damaligen Zeit angesteckt, daß für uns die Wahrheit der Welt nur im Frieden zu finden war. Wien in Trauer, ohne seine Leichtlebigkeit, wäre nicht Wien. Aus reiner Schizophrenie zögerte ich, unsere Pläne zu ändern, aber Sartre wollte sich um nichts in der Welt in einer Stadt langweilen, die von einem absurden Drama entstellt wurde. Wir wollten einfach nicht glauben, daß durch das Attentat auf Dollfuß das wahre Gesicht Österreichs, Europas zum Vorschein kam. ${ }^{220}$

(Nous comptions nous rendre à Vienne. Mais en sortant de l'hôtel, un matin, nous vîmes des rassemblements dans les rues; les gens se disputaient les journaux aux énormes manchettes où nous distinguâmes le nom de Dollfuss et un mot commençant par $\mathrm{M}$ dont nous devinâmes le sens. Un passant qui parlait allemand renseigna Sartre: Dollfuss venait d'être assassiné. Il me semble aujourd'hui que c'était une raison de plus pour nous précipiter à Vienne. Mais nous étions tellement imbus de l'optimisme de l'époque que, pour nous, la vérité du monde c'était la paix; Vienne en deuil, privée de ses grâces légères, ne serait plus Vienne. J'hésitai, par pure schizophrénie, à changer nos plans, mais Sartre refusa catégoriquement d'aller s'ennuyer dans une ville défigurée par un drame absurde. Nous ne voulions pas penser que l'attentat contre Dollfuss révélait au contraire l'authentique figure de l'Autriche, de l'Europe.) $)^{221}$

Stattdessen unternehmen Beauvoir und Sartre eine Reise durch Deutschland und durch Tirol, Salzburg und das Salzkammergut, die überwiegend touristisch ausfällt:

Sogar in Österreich erschien die Atmosphäre uns weniger drückend als in Deutschland. Innsbruck gefiel uns und Salzburg noch mehr, die Häuser aus dem achtzehnten Jahrhundert mit ihren vielen Fensterscheiben ohne Läden, die schön gearbeiteten Wirtshausschilder, die an den Fassaden hingen: Bären, Schwäne, Adler, Hirsche, aus patiniertem Kupfer geschnitten. In einem kleinen Theater führten entzückende Marionetten Mozarts Entführung aus dem Serail auf. Nach einer Busfahrt ins Salzkammergut kehrten wir nach München zurück. ${ }^{222}$

(Même en Autriche, l'air nous sembla plus léger qu'en Allemagne. Innsbruck nous plut, et davantage encore Salzburg, ses maisons du XVII ${ }^{\mathrm{e}}$, avec leur multitude de carreaux sans contrevents, les enseignes délicates qui se balançaient aux façades: ours, cygnes,

220 Beauvoir: In den besten Jahren, S. $166 \mathrm{f}$.

221 Beauvoir: La Force de l'âge, S. $222 \mathrm{f}$.

222 Beauvoir: In den besten Jahren, S. 167. 
aigles, daims découpés dans du beau cuivre patiné. Dans un petit théâtre, des marionnettes charmantes jouaient L'Enlèvement au sérail de Mozart. Après un tour en autocar dans le Salzkammergut, nous revînmes à Munich. $)^{223}$

Als sie 1954, also 20 Jahre später, kurz vor der Wiener Pressekonferenz im Hotel Sacher, von Straßburg aus eine Tour durch Süddeutschland unternehmen, fällt Beauvoir auf, wie sie sich dort 1934 weigerten, dem drohenden Unheil ins Auge zu sehen, außerstande, seine Ungeheuerlichkeit zu ermessen. (,[E]n 1934, nous marchions sur ces remparts, refusant d'affronter l'imminente catastrophe, incapables, même Sartre qui avait l'imagination du malheur, d'en pressentir l'énormité.“'224) Beauvoirs Ton ähnelt jenem Sartres, der in Qu'est-ce que la littérature? sich und den anderen intellektuellen Opfern des Desasters von 1940 (,victimes du désastre de $40^{\text {، } 225}$ ) eine Mitschuld an der Katastrophe des Zweiten Weltkriegs zuweist, weil sie sich nicht am Vorabend vor, sondern am Morgen nach dem letzten Umsturz der Geschichte geglaubt hatten. Dass das Versäumnis, rechtzeitig gegen das Unrecht anzugehen, Sartre zur Überkompensierung antreibt, ist eine verbreitete Erklärung für nachfolgende unverhältnismäßig wirkende Handlungen. Er sei „obsessed with the need to avoid making the same mistake again“, schreibt Judt, womit „the most rigid and extreme positions“"226 einhergingen. Die Angst, erneut nicht auf der Höhe der historischen Ereignisse zu sein, bedingt auch laut Jean Améry Sartres spätere „realpolitisch aussichtslose“ und „vor dem Exzeß nicht zurückscheuende [...] revolutionäre [...] Haltung،‘227. Gerade sein Eintreten

223 Beauvoir: La Force de l'âge, S. 224. Bevor Beauvoir in den fünfziger Jahren Wien zum ersten Mal bereist, lebt schon ihre jüngere Schwester, die Malerin Hélène de Beauvoir, in der Stadt mit ihrem drei Monate nach Kriegsende für zwei Jahre dorthin versetzten Gatten, dem Diplomaten Lionel de Roulet. Cf. die Beschreibungen im Kapitel „Vienne Trafique-City“ in Hélène de Beauvoirs Buch Souvenirs (Recueillis par Marcelle Routier. Paris 1987) über die in Wien herrschende ,Dritter Mann'- bzw. ,Hitchcock-Atmosphäre‘, mit Schwarzmarkt, nächtlichen Schüssen, Ruinen, Hunger und einer sich unterwürfig verhaltenden Bevölkerung.

224 Beauvoir: La Force des choses, Bd. 2, S. 51. Die Volksstimme, das Zentralorgan der KPÖ, erwähnt schon am 29.09.1962 (e.sch.: Ein Leben mit Sartre) diesen Aspekt: „Unbeholfen und vielleicht auch mit zuviel Distanz standen Simone de Beauvoir und Jean-Paul Sartre anfangs zur Politik. Ihre individualistische Art, zu reagieren, spiegelte sich in dem Entschluß, auf einer Reise durch Mitteleuropa Wien zu meiden.“

225 Sartre: Qu'est-ce que la littérature?, S. 239.

226 Judt: Past Imperfect, S. 56.

227 Améry: Sartre: Größe und Scheitern, S. 253. 
für die Sowjetunion und sein Bruch mit ihr lassen sich mit Alfred Betschart als „,von besonderer Radikalität“‘228 einschätzen.

Die Idylle zwischen Sartre und der Parti Communiste (,idylle sartre-communiste“2229) hält nur vier Jahre: Schon angekratzt durch Uneinigkeiten bezüglich des Algerienkrieges 1954, zerbricht sie am sowjetischen Einmarsch in Ungarn $1956^{230}$ (und vollends 1968 in Prag). ${ }^{231}$ Améry, der Sartre in „getreuer Gefolgschaft، ${ }^{\text {232 }}$ und nach eigenen Angaben mehr oder weniger mechanisch folgt und sich erst zu Zeiten der Critique de la raison dialectique (1960) über „die Fragen von Revolution und Violenz“،233 von ihm löst, verortet Sartres

228 Betschart: Sartre und die Sowjetunion, S. 56.

229 Cohen-Solal: Sartre, S. 569.

230 Es ist dies eine Zäsur für viele Gleichgesinnte wie Günther Anders, der sich Sartre gegenüber „[s]olidarisch mit Ihrer Desolidarisierung“ erklärt. In seinem Brief vom 4. Dezember 1956 versucht Anders überdies (untypischerweise in deutscher Sprache), Sartre zu einer „Rettungsaktion“ für Georg Lukács zu bewegen, von dem man zuletzt gehört habe, er sei Teil der verschwundenen Gruppe Nagy: „Hier in Wien ist aber nichts zu tun moeglich. Einmal deshalb nicht, weil es garkeine von Parteien unabhaengige ,Intelligentsia' hier gibt; und weil jeder Angst hat, sich [durch] die Tatsache, dass er den oder jenen zu retten versucht, selbst zu gefaehrden“. Briefwechsel Günther Anders - Jean-Paul Sartre. 25.09.1945-17.07.1970. Literaturarchiv der Österreichischen Nationalbibliothek, Wien (LIT), Sign.: 237/B1508.

231 Der Bruch von 1956 ist kein vollständiger. Der Journalist François Fejtö, dessen Betrachtungen in La Tragédie hongroise (Paris 1956) Sartre in einem „Lettre-Préface“ (S. 13-15, hier S. 15) als Wahrheit („la vérité“) über Ungarn bezeichnet, wundert sich, dass der Autor einige Monate später wieder ,an den Versammlungen der Sowjetisch-Französischen Freundschaftsgesellschaft“ teilnimmt. Sartre habe ihm erklärt: „,Mein Lieber, Sie wollen nicht verstehen, daß ich ein Revolutionär bin. Ich will die Revolution in Frankreich. Wie glauben Sie, kann man in Frankreich ohne die Kommunisten und die Kommunistische Partei eine Revolution machen?““ Fejtö, im Gespäch (1998) mit Ulrike Ackermann. In: Ackermann: Sündenfall der Intellektuellen. Ein deutsch-französischer Streit von 1945 bis heute. Stuttgart 2000, S. 102.

232 Jean Améry: Revision in Permanenz. Selbstanzeige im Zweifel (1977). In: Améry: Werke, Bd. 7: Aufsätze zur Politik und Zeitgeschichte. Hg. von Stephan Steiner. Stuttgart 2005, S. 568-572, hier S. 569.

233 Améry: Lefeu oder Der Abbruch, S. 162. Der Akt der Gegengewalt, den Améry hier diskutiert, mit großem Verständnis für die „Zurücknahme des Erlittenen durch den Akt des Erleiden-Machens“ (S. 134), könne keine Maxime sein. Was Sartre im Vorwort von Frantz Fanons Die Verdammten dieser Erde vorschlägt, empfindet er als unmöglich: „[W]enn Sartre sagte, mit der Exekution eines Kolonialherrn stürben zwei: der Herr und der Knecht, dann ist das nur die Pointe, nicht aber ein gesellschaftlich mögliches Programm.“ (S. 142) Sartre impliziert hier, dass der Unterdrückende durch seine dehumanisierenden kolonialistischen Praktiken selbst auch unterdrückt ist: „,[E]inen Europäer erschlagen heißt zwei Fliegen auf einmal treffen, nämlich geleichzeitig einen Unterdrücker und einen Unterdrückten aus der Welt schaffen. Was übrigbleibt, ist ein toter Mensch und ein freier Mensch.“ („[A]battre un Européen c'est faire d'une pierre deux coups, supprimer en même temps un oppresseur et un opprimé: restent un 
Größe gerade darin, dass er im Zuge „des ununterbrochenen geistigen Sichselbst-Überschreitens“ bereitwillig den jeweils „,vorangegangenen Sartre“234 demoliert. Dass er sich im Umgang mit den KommunistInnen einmal mehr „der Genugtuung des Rechtbehaltens“235 versagt, sieht mit aller Selbstverständlichkeit (da das existentialistische Denken ,wandlungsfähig“'236 und -bedürftig ist und daher stets seiner Zeit anzupassen) auch Sartre selbst positiv: Die ,Irrtümer erlauben ihm schließlich, sich jedes Mal ein wenig zu verändern („de changer un peu à chaque fois“(237).

homme mort et un homme libre [...].“) Jean-Paul Sartre: Vorwort. In: Frantz Fanon: Die Verdammten dieser Erde. Frankfurt am Main 1966, S. 7-25, hier S. 18 (Jean-Paul Sartre: Préface [1961]. In: Frantz Fanon: Les damnés de la terre. Paris 2002, S. 17-36, hier S. 29). In Lefeu oder Der Abbruch geht Améry zuletzt auf Abstand zu Sartres ,Anarchismus' mit folgenden deutlichen Worten: „Er hält sich starr, marschierend linkswärts, agitiert auf seine immer absurdere Weise - attention, imbécile, tenez votre droite! - und schreibt, daß Wahlen in diesem Lande nichts seien als Spiegelfechterei, elections, piège à cons. Erreicht gar nichts mehr damit. Der Name verblaßt, die Spießer zucken die Achseln: Sartre? Un con. Un con. Dahin ist es gekommen. Ein Name blaßt aus vor meinen angestrengten Augen und ich muß zusehen, nicht nur widerstandslos, sondern billigend.“ (S. 97) .

234 Améry: Sartre: Größe und Scheitern, S. 239.

235 Améry: Unmeisterliche Wanderjahre, S. 91.

236 S. F.: Besuch bei Jean-Paul Sartre. In: Die Presse, 12.07.1952.

237 Sartre: Jean-Paul Sartre. In: Chancel: Radioscopie III, S. 241. 